LIRRARY

CF THE

UNIVERSITY

OF

SALIFORN

BIOLOGY

LIBRARY 
Wratew a collabonten woth H.C.

thenche 



\title{
What You Ought To KnOW ABOUT YOUR BABY
}

By LEONARD KEENE HIRSHBERG, B.A., M.D.

争

\begin{abstract}
A Text Book for Mothers on the Care and Feeding of Babies, with Questions and Answers Especially Prepared by the Editor
\end{abstract}

?

PUBLISHED BY

THE BUTTERICK PUBLISHING COMPANY BUTTERICK BUILDING 1910 NEW YORK 


\section{BioloGY \\ LIBRARY}

Copyright, 1910, BY

THE BUTTERICK PUBLISHING COMPANY NEW YORK 


\section{TABLE OF CONTENTS}

PAGE

1. THE SLAUGHTER OF THE INNOCENTS • • . . - 1

II. THE NEW-BORN BABY • . . . . . . . 13

III. THE BABY'S FIRST FEW MONTHS - • • - 17

IV. THE NURSING BABY $\quad$ - $\quad$ - $\quad$ - $\quad$ • $\quad$ - 21

V. MOTHER AND BABY • • • • • • • 26

vI. THE BOTTLE-FED BABY • • • • • • 30

VII. A CHAPTER ON MILK • . • . • . . 36

VIII. THE FOOD FOR GROWING CHILDREN • • • • 42

IX. WHAT YOU OUGHT TO KNOW ABOUT YOUR SCHOOL - 51

X. NeEd EVery Child have CATChing Diseases? - $\quad 59$

XI. IF YOUR BABY HAD DIPHTHERIA — . . . . $\quad$ - 61

XII. IF YOUR BABY HAD SCARLET FEVER - . . - 71

XIII. WHOOPING COUGH. IT KILLS MORE THAN DIPHTHERIA AND SCARLET FEVER TOGETHER . . . . . . 79

XIV. IF YOUR BABY HAD PNEUMONIA - • • • • $\quad$ - 85

XV. NEED EVERY CHILD HAVE MEASLES? - • • - 91 
Appreciatively dedicated to $\mathrm{Mr}$. George W. Wilder, whose earnest efforts for the child's broader welfare prompted this book. 


\section{A WORD TO MOTHERS}

This is a book that The Delineator sends to mothers because we believe that the American woman needs a knowledge of child hygiene. The census statistics show that one in every six of the children born in the United States does not live to be one year of age. A great many of those who survive grow up to a life of suffering and incapacity, handicapped in the struggle of existence, for from 70 to 90 per cent. of American school-children have one or more physical defects. The conservation of humanity, the perfection of the race, is the watchword of to-day. More and more the doctor is interpreting it as his mission to teach people how to keep well. And the place to begin is with the babies. Mother instinct has done much through the ages. But mother training equipped with all the knowledge that science can give, may do much more. For the new motherhood that shall know how, this book is published. 
Digitized by the Internet Archive in 2007 with funding from Microsoft Corporation 


\section{CHAPTER I.-THE SLAUGHTER OF THE INNOCENTS}

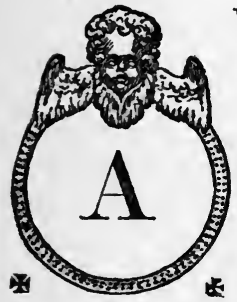

WOMAN enters a car with a baby in her arms. An old gentleman rises and gives her a seat beside another woman. The baby begins to cry. The mother bounces him up and down.

"I suppose the poor little dear is teething," ventures the stranger affably.

"Yes," replies the mother. "He cut two him all out of sorts. Last night he had a croupy attack, and if I hadn't given him a dose of ipecac at once we might have had to send for the doctor."

The mother takes a milk bottle from her satchel, carefully wipes the nipple with a rag, and gives it to her offspring. A gurgleand he is still. The women talk on. The child empties the bottle and begins to fret again. The mother produces a rubber "pacifier" from her capacious hand-bag, and he begins to gnaw it.

"Is he a good child?" asks the stranger.

"A real angel," replies the mother proudly. "He never wakes more than twice a night, and then a half-bottle of milk quickly quiets him. My mother has taken complete charge of him. She has raised eight children and knows more than the doctor. She won't let me give him anything but boiled milk."

A common enough conversation, certainly. You have heard it yourself a dozen times, in trolley car and train. It seems utterly harmless - and yet there is in it evidence enough to convict the mother of no less than seven separate and distinct crimes-of omission, commission, ignorance, indulgence and superstitionagainst her innocent youngster, and, indirectly, against posterity, her country and long-suffering humanity.

Let us go back and listen again. The woman enters the car. The baby begins to cry. She bounces it up and down. Crime number one! Babies should not be bounced up and down. It nauseates them; it strains them; it makes them unhappy. 
The baby is teething. "It's put him out of sorts." Crime number two! - this time one of superstition. Teething does not put a healthy baby "out of sorts." If the little fellow is a normal child his teeth come through the gums without pain. If he cries at the time, the chances are that it is because maternal ignorance has given him bad habits. If that is not true, he is sick, and the chances are that the sickness has its seat, not in his gums, but in his stomach.

"Last night he had a croupy attack, and if I hadn't given him ipecac." Crime number three! For true croup, ipecac is no remedy. For a slight cough-and most mothers group all dry coughs under the generic name of "croup"-no medicine is needed. The ipecac makes the little dear vomit; he becomes exhausted and falls into a heavy sleep. Nature cures his cough.

The mother takes a bottle from her hand-bag., wipes the nipple and gives it to her offspring. A gurgle-and he is still. Crime number four! The hand-bag is full of germs, the nipple is full of germs, the rag used to wipe it is full of germs and the bottle is full of germs. Yet the baby lives! And why? Because the human body is so tough that nine times out of ten, in a battle with germs, it wins. But the tenth time it loses.

The child empties the bottle and begins to fret. The mother produces a "pacifier." Crime number five! The "pacifier" is evois dirtier than the milk bottle. Germs thrive upon it like barnacles upon a floating log. If the baby is in luck they are the comparatively mild and puny germs, that cause blisters in the mouth, sore gums, stomach-ache, diarrhea and rashes. If fortune frowns upon him, they are the virulent and deadly germs of cholera infantuni.

The baby is an angel. "He seldom wakes more than twice a night." Crime number six!-this time one of maternal fondness. A healthy baby should sleep from dusk to dawn without waking. If he doesn't, it is because his mother has permitted him to acquire bad habits.

"My mother has taken charge of him." Crime number seven! True enough, the dear old lady has raised eight of her own. But the acts of her daughter prove that she still clings to a whole confession of ancient delusions. She believes, for instance, that normal teething should torture babies and make them cry. She believes that babies should be nauseated with ipecac whenever they happen 
to cough. She believes that wiping a rubber nipple with a rag makes it clean. She believes that babies should be bounced up and down, and that, when they cry, they should be given "pacifiers" to gnaw. She believes, in a word, in medical fallacies that were venerable in the days of Hippocrates. And yet she "knows more than the doctor!"

Is the picture overdrawn? Is it a farce? Not at all. Look at it squarely and you will see that it is tragedy-tragedy of the gloomy, every-day sort we have learned to watch unheeding. A hundred thousand American babies die every year. Fully half of these deaths are the sad result, I believe, of unwise feeding, of stupid dosing, of precedent, habit, custom and superstition.

On the face of it, of course, it seems reasonable to maintain that a woman who has brought up eight children of her own, and watched by the bedsides of perhaps a dozen others, should know something about the art. But this conclusion is based upon faulty logic.

The fact that grandma's eight children lived shows only that they were sturdy and lucky-that their natural recuperative powers enabled them to survive her blunders or they that were rescued by some hard-working family doctor. The knowledge that she acquired in raising them consists, in good part, of things that are obviously untrue. Because she once, or twice, or eight times observed that a certain procedure seemed to be followed by a certain result, she maintains, to-day, as an uncontrovertible proposition, that that same procedure will be followed by that same result inevitably and always.

The doctor is a mere man, and it may be he has no babies of his own, but his knowledge of babies, even accepting the grandmother's test, is infinitely greater than her own. He has walked the hospitals for five years and he has seen and studied, not eight babies, but eight hundred or a thousand. He has read the books; he has listened to the great physicians. He has given his days and nights to the investigation of human maladies-their cause and their cure.

And so, is it not reasonable, when he says that contaminated cow's milk is not good for babies, and that "pacifiers" are likely to inoculate them with the germs of cholera infantum-is it not reasonable to set up his authority against that of the grandmother whose eight babies were lucky and so faced these perils unslain, if not unscathed? 
Two considerations must be kept ever in mind in discussing the care of infants. One is the fact that silly superstitions, far from being confined to the slum mothers who give their babies beer and dress them in wadded flannels, are rampant to an astonishing degree among women otherwise intelligent and presumably sane. The other is the fact that the ignorance of the mother, even when the baby passes childhood in apparent health and safety, often paves the way for suffering later on.

The tendency to blame all sorts of things upon intestinal parasites affords a double illustration. A baby, let us say, is restless and fretful. Its body twitches and it moves about in its sleep.

It awakes suddenly and with a frightened cry. By day it squirms in its high chair, picks at its nose and scratches the back of its neck. Its mother is alarmed, and so its grandmother, two aunts and four neighbors are called in consultation. The grandmother has raised eight children; the aunts, between them, have raised nine; and the neighbors point proudly to twenty. Here we have a gigantic conglomeration of expert aid. Thirty-seven human beings are monuments to the science of seven mothers.

"The poor dear has worms," says the grandmother.

"Give him some quassia," says one of the aunts.

"Why not try turpentine?" says the other.

"Or cucumber seeds," suggests one of the neighbors. "Wnen my little Johnnie-

So the corner druggist makes a sale of shop-worn goods, the child swallows a staggering dose-and during the ensuing forty-eight hours it spends most of its time in a stupor that seems like sleep. Isn't this a proof that it has been cured-by the quassia, the turpentine or whatever other specific the seminary of experts agreed upon? Of course it is!

But all the same a rash intruder might make the observation that babies are not designed by nature for the ingestion of drugs, that a comparatively small dose shocks and exhausts them, and that this exhaustion is often mistaken for healthy and refreshing slumber. And this same observer, sometime later on, might point out that the baby is again wakeful and restless-that it again squirms in its bed and chair and again cries in the night.

In the end, perhaps, it ceases its troubling, and the "cure" is ascribed to the repeated doses that have been forced down its throat. But, on the other hand, there is a chance that it will show no im- 
provement, and that its father, with courage born of alarm, will at last invade the prerogatives of the feminine side of the house and call in a physician. The physician, if all of his honesty has not oozed out of him, will make a thorough examination, and the probability is that he will find the baby to be suffering from adenoids or, perhaps, St. Vitus's dance.

Adenoids are curious little cauliflower-like growths which appear at the juncture of the nasal cavity and the pharynx. They are often observed at birth, but they seldom cause discomfort until some months later. Then they interfere with respiration and cause the baby to be restless. It tosses in its sleep and wakens suddenly, crying out as if in distress.

If adenoids are permitted to remain they deform the mouth, teeth, throat, chest and face. At their worst they produce popeyes and what is called a frog-face. They cause mouth-breathing, with all its attendant evils. They open the way for a hundred and one ills, from rupture of the ear-drum, running from the ears, coughs and tonsilitis, to pulmonary tuberculosis.

A slight operation suffices to remove them. The baby suffers little pain and loses little blood. Out they come-and with them the overgrown tonsils that commonly accompany them. If they are suffered to remain, they may never be discovered. But it is certain that in one way or another, they will cause damage.

The mother of eight may say that she never heard of adenoids. But despite her reluctance to include them in her lexicon, they actually do exist. One child in every three has them. In lowlying sea-coast towns they may be found in two children in every three. A generation ago they were unobserved, and it is only for a decade or so that their great importance has been fully realized. And so it is no wonder, perhaps, that the average grandmother is unaware of them. But the poor baby! It pays for her ignorance-in pain, wakeful nights and misery, now and hereafter!

Given a child born at full term and of healthy parents, and it is safe to say that half of its infantile ills are due to the ignorance of its mother. She loves it, and so, when it sets up a cry, she nurses it-and it becomes an ill-mannered little glutton, with a penchant for colic. She loves it, and so she feeds it too often and too muchand it becomes ripe for cholera infantum. She loves it, and so, after it has had its fill, she coddles it, bounces it and plays with it-and it vomits. 
Despite the general idea that some babies are foreordained to suffer from colic and that nothing can save them, it is nearly always preventable. Its appearance indicates that the little sufferer is getting food of a sort his stomach can't digest, and missing food of the sort he needs. It means that his mother, if he is at the breast, is in no condition properly to feed him. It means that the infant food he is taking, if he is upon the bottle, is poisoning him. The remedy in each case is a consultation with a competent physician. This man, though not a mother himself, will determine exactly what the baby needs, and he will write a prescription that will insure the baby's getting it.

The word "prescription" may suggest the idea of drugs-of paregoric, ipecac, spirits of nitre and all the other ancient contents of the infantile medicine-chest-but in this case the prescription will be, not for drugs, but for milk. What the baby needs is pure, nourishing food, and, failing a good maternal supply, the best food he can possibly get is cow's milk-cow's so modified that it contains the exact amount of proteids, of sugar and of fats that he needs.

In all large cities there are now laboratories, in charge of skilled men, which make a business of supplying cow's milk that has been modified according to physicians' prescriptions. Plain cow's milk is bad for babies, even after it has been boiled, because it lacks certain constituents that they need, and contains others that they should not be called upon to digest. The work of modifying it is done scientifically and cleanly, and the result is the nearest approach to a perfect food that science has yet evolved.

The laboratory man will compound this, and the result will be a bottle of milk - of milk that seems to the feminine expert to be quite like ordinary milk. But when the sick baby has taken it at the hours and intervals laid down by the physician he will have colic no longer, and in the process he will have acquired good habits.

The notion that constant nocturnal bawling is a diversion necessary to the baby's well-being is a fallacy as old as the superstition that sulfur and molasses are good for the blood. If an infant wakes and cries at night it is an evidence of one of two thingseither it is ill or it has been permitted to acquire bad habits. If it is ill, the best thing to do is to send for a doctor.

If, after a thorough examination, he decides that it is in good health, the fault lies with its mother. She fed it whenever it 
cried; she made it associate the act of crying with the production of a meal; she fastened upon it the habit of feeding when it should be asleep.

A healthy infant, properly trained, should go to sleep every night at seven o'clock and sleep soundly until daylight. It should be fed when it awakes in the morning, and it should be fed again at regular intervals throughout the day-every two hours when it is very young, and every three or four hours as it grows older. Its last meal should come just before it is tucked into its crib. And if it cries for food after that, it should be permitted to cry until the habit is broken.

The only things that should ever touch an infant's lips, during its first year, are boiled water and milk-mother's milk, or cow's milk properly modified. If it is born strong and sound and is properly fed it will need no medicines. And all other thingsmush, soup, porridge, fruits, pretzels, alcohol, vegetables, meats, "pacifiers," rubber rings, orris-root, sugar, rattles and its nurse's fingers-are abominations in its mouth. They spell indigestion in a dozen forms, not to speak of colic, fevers, wakefulness, faulty growth and cholera infantum.

Next to unwise feeding, as a source of infantile ills, comes overcoddling. Kissing the baby after it has been fed, for instance, is very likely to cause it to vomit, and vomiting is even more exhausting to a child than to an adult. The desire of all aunts, cousins, sisters, grandmothers, neighbors, parlor maids, cooks, seamstresses and other members of the affectionate sex to "hold the baby" and kiss it, and of all uncles, grandfathers and bachelor friends of its father to hoist it to the ceiling, should be rigorously denied. Such delightful domestic pastimes do the baby no good, and very often hurt it. At best it becomes peevish. At worst it shows signs of hysteria. Children should play-when they are old enough to play - with children.

And let there be an end to home doctoring! Most intelligent mothers have learned to be wary of soothing-sirups, but the great majority still put a good deal of faith in paregoric. It is a favorite for diarrhea, stomach-ache and a host of other ills. Often, perhaps, it gives what seems to be relief, since opium, its main constituent, is the greatest of the gifts of the gods. But is it safe for mothers to give their children opium?

In most other home remedies there is less positive danger, but 
all of them do harm in at least two ways: they postpone the beginning of proper treatment, and they subject the poor baby to excessive and harmful medicating.

Deliberate neglect of her baby is a felony seldom proved against an American mother-or against any mother, for that matter. Yet I sometimes feel that neglect, in the long run, would often do less damage than too much loving. The classical "villainess" of American romance and folklore, who wastes her time in social gaiety and hands over her offspring to professional nurses, seems like some revolting and inhuman monster, and perhaps she is. But did it ever occur to you, oh, indignant critic, that the children of such callous mothers, though they may lack a proper reverence for the canon law and the ordinances against motor speeding, are nevertheless uncommonly healthy animals? The fashionable young woman appears in the divorce courts a bit too often, but she seldom lands in a hospital. She is vigorous and strong. She has a sound digestion. She swings her golf club with muscular arms. And her brother is tough-literally as well as figuratively. $\mathrm{He}$ has no morals, but he has a good wind and strong legs.

The cause of all this, I fancy, lies in the fact that these young persons were never coddled. Professional nurses fed them, with inhuman disregard for their yells, upon proper food at proper intervals. An early realization of the futility of bawling led them into regular habits. They swallowed no soothing-sirups; they took no camomile; they knew not the flaxseed poultice nor the home-made liniment. No one rocked them to sleep; no one tickled them; no one bounced them up and down. They were kissed only upon state occasions-and then in a gingerly, aseptic way, upon the forehead or the cheek.

Consider now the baby of the great middle class-the baby enthroned upon a mountain of pillows, the baby whose mother trembles when he cries and worries for days about the mole on his neck and wears herself out slaving for him. How zealously she guards him against drafts! He is clothed in warm flannels; his cradlehe should really sleep in a comfortable crib-is dragged far from the window; he is buried in bedclothes, and he is kept indoors on windy days. The mother's intentions are good, beyond a doubt, but her prophylaxis is hopelessly fatuous. The baby needs air beyond all things. He should spend as much as possible of his first year in the open. He should be taken out in his go-cart 
upon every fair day, and kept out in all the intervals between meals. He should sleep in a room with open windows, Winter and Summer.

Babies should be put into short clothes at their birth if they come into the world in warm weather, and at two months if they first see the earth in a mantle of snow, and thereafter they should be clad very sparingly.

An infant's skin is so tender that perspiration quickly causes it to chafe. To guard against this the baby should be kept cool and bathed often. And after it has been bathed it should be laid on a clean sheet and not first frescoed with powder and then swathed in habiliments fit only for a mummy.

In Winter the fact that the weather is cold should not condemn the child to hot rooms and bad air. It is easy enough to dress it warmly without burying it in clothes, and if it is warmly dressed the cold will not hurt it. Let it not be understood that I am arguing that infants are fit to face blizzards. But in most parts of the United States blizzards are rare, and the majority of Winter days, though cold, perhaps, are fine. On such days the baby should spend hour after hour outdoors. Awake or dozing, it should be wheeled up and down in the pale sunshine.

The popular notion that all babies are predestined to suffer attacks of a long string of infantile ills, from chicken-pox to diphtheria is utter foolishness. There is no reason, whatever, why a child should take any of these diseases. A baby that has grown accustomed to sunlight and the open-that sleeps soundly, digests normally and has lost, seemingly, all capacity for taking cold-is little likely to fall a victim to the common infections. Its veins are full of good, red blood, and this blood is prepared, at all times, to wage a terrific war upon germs. And even in case the germs prevail, and the baby grows ill, its chance of having but a mild attack and of recovering quickly and without distressing and lingering complications is infinitely greater than that of the vulnerable, ailing, coddled child. The evil effects of coddling do not appear at once. If they did, there would be no coddling. But they appear certainly, none the less, and too often they make the difference between a mild case of scarlet fever and a very bad one, with Bright's disease following after.

The baby that is fed every time it cries, whose stomach is overloaded day and night with improper food, is the baby that falls 
before the germs of cholera infantum. This is less often a malady of filth-in the popular conception of the word-than a disease bred of faulty nutrition, overbundling and grandmotherly therapeutics. A flaxseed poultice may lay the foundation for pneumonia. A drop of paregoric may kill. A mistaken diagnosis of "worms" may mean St. Vitus's dance, or adenoids and long years of suffering. A flannel garment may pave the way for measles or diphtheria. A home-brewed tea may delay the physician until it is too late. A kiss may spell tuberculosis.

Home dosing and coddling-herein we have the foot-notes that explain the tables of infant mortality. Throw away your paregoric, your ipecac, and your camomile! These things are abominations as bad as your patent soothing-sirups and sarsaparillas. Your baby doesn't need drugs, but pure food and fresh air. If he seems ill, let your doctor prescribe for him. Nine times out of ten he will order milk rather than purges. Open the windows and let in the air! Throw away your stock of chest-protectors, bellybands and padded woolens! Let the baby kick! Let him breathe! Let him be bare!

\section{QUESTIONS FOR THE MOTHER ABOUT CHAPTER I}

Is there anything you would not do to save your baby?

No.

Is anything too good for your baby?

No.

Do you want the best advice in bringing up your baby?

Yes.

Is grandma's advice or your neighbor's advice the best?

No.

To whom can you safely trust your baby?

To the doctor.

Should a mother wait till her baby is sick before taking it to the doctor?

No. The doctor can tell a mother many things about the care of her baby that will keep it from getting sick.

How often should your doctor see your baby, whether it is well or sick?

At least once in two weeks until two years old. 
Is this not an unnecessary extravagance?

No. The cost of a ten minute examination of the baby by the doctor once in two weeks will, in the long run, be very much less than the cost of the doctor's visits and the bills for medicines if the baby has a severe illness.

How many babies die under one year of age in the United States to-day?

One out of every six babies born dies before it reaches one year of age. One out of every four babies born dies before it reaches five years of age.

Shall your baby be the sixth one?

No.

How can you save it?

By striving to learn the best methods known by experts on feeding, clothing and caring for the baby.

What are some of the superstitions and customs of mothers that make babies sick?

Soothing sirups; pacifiers; feeding the baby whenever it cries; patent medicines; patent baby foods; family remedies; the idea that babies are doomed to be sick when their teeth come; that the baby must be constantly played with or kept in constant motion; the idea that because so many babies die to-day they must always die.

What are the diseases of which babies die?

Diarrhea; pneumonia; whooping cough; tuberculosis; meningitis and a few of contagious diseases such as diphtheria; measles and scarlet fever.

How many of these diseases are preventable?

All of them.

How many of them are due to ignorance on the part of the mothers? All of them.

How many of them are germ diseases?

All of them.

How do germs get into the babies' system?

Through impure milk; through sucking a dirty pacifier or rag; through drinking water that has not been boiled; through nursing bottles and nipples that have not been sterilized.

What is the best way to make a baby able to resist germs?

By keeping it out in the air all the time, and by being sure that it is well nourished. 

bad?

Why is the pacifier habit or the habit of sucking the thumb especially

Because it forms the habit of breathing through the mouth. This encourages the growth of adenoids. Because the tissues of the throat become infected with germs taken in this way.

What are adenoids?

Adenoids are small spongy lumps that grow back of the nose and partly close the nostrils.

Why should adenoids be removed?

Because if permitted to remain in the growing child, the mouth, teeth, face and chest become deformed; because they are the direct cause of deafness, constant colds and throat trouble, and often lead to pulmonary tuberculosis.

How can adenoids be removed?

By a slight surgical operation which can be performed in less than a minute and which causes very little pain, and but slight loss of blood.

Why are mothers glad when they have not delayed in having adenoids removed?

Because the change in the health and happiness of the child is so immediate and so marked.

What is the young mother's gospel?

Clean air, clean milk, clean baby. 


\section{CHAPTER II.-THE NEW-BORN BABY}

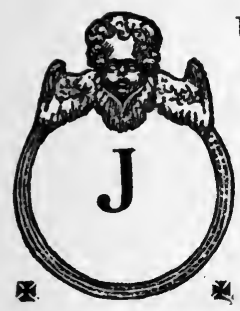

UST as every man is firmly convinced that he is perfectly competent to drive a nail, run a newspaper or direct the destinies of the nation, so every woman believes that she knows how to care for a baby. The only difference is that the man looks upon his fitness as the result of profound study and a high order of intellect, while the woman, more modest, gives the credit to instinct. Both are wrong.

Instinct and mother love, it is plain, will restrain even the most ignorant young mother from feeding her baby upon cucumbers, but in other ways, unless she is well instructed, she is apt to make mistakes, and these mistakes may be costly. If the instruction she receives comes from one of those well-meaning old women who radiate maternal lore so copiously in all communities, her blunders are certain to be numerous and bad. But if she is sensible, and seeks advice from a physician or a graduate nurse, she will learn a great deal, and the things that she learns will have the merit of being true. With a good groundwork thus laid, she will approach unaccustomed problems and emergencies in an intelligent, efficient fashion.

In choosing the physician who is to assist in bringing her first child into the world, it is well for the young mother to be extremely critical. Unluckily enough, all holders of the doctor's degree are not of the first rank, and very often the man with the most impressive beard and of the most heartening geniality is the least competent.

The best thing to do is to select a practitioner who has been trained in a college of the best sort and who, whether young or old has standing in his profession. If he is of such admitted competence that his fellow physicians are known to seek and respect his advice, so much the better.

Most towns will have a doctor of hospital experience and skill in conducting infant cases. His fees may seem large, but he 
well earns them, for his presence is an assurance against many very distressing accidents. The majority of the dangers attending childbirth, indeed, disappear with scientific care. This is especially true of the complications due to infections-childbed fever and blood-poisoning in the mother, and that appalling eye inflammation which leads to blindness in the child. It has been estimated that nearly half of the blindness in the United States today had its origin in infections at birth. A scientific physician knows how to prevent such accidents with almost absolute certainty, but the ordinary neighborhood midwife does not.

The average weight of a white American baby, at birth, is seven and one quarter pounds, but a child may weigh little more than six pounds and still be perfectly healthy. The twelve-pound baby of popular tradition is very rare in fact, and his celebrity is largely due to inaccurate scales and heavy clothes. A child of abnormal size is not to be envied, since he is usually no stronger than a smaller one, and his entryl into the world is attended by far greater hazards and difficulties.

A new-born baby appears such a tiny and distorted caricature of a human being that it is often difficult to convince the alarmed mother that nothing is wrong with it. In color it is a fiery red, and in expression it is utterly vacuous. Its head is large and oblong, and there are spaces between the soft bones of its skull through which the movements of its brain may be observed. The oblong shape of the head soon gives way to rotundity, and the process requires no artificial aid. The notion that the contour of the skull may be modified by the manner in which the child is laid upon its bed has little basis in fact. So long as it is comfortable and has a soft pillow under it, it is safe.

An infant's abdomen appears enormous, just as its chest appears small. This is because at birth, the development of its digestive apparatus has proceeded much further than that of its respiratory organs. For a week or so its breathing may be quick and irregular. Sometimes it will miss a breath, and then again it may breathe so fast that it seems to be suffocating. Do not worry. It is merely a way that new-born babies have.

During its first week the child is apt to lose its red color and become yellowish. Many midwives note this as a dangerous sign, and proceed at once to dose the little one with honey, sulfur and various teas. As a matter of fact, the yellow color is nothing more 
than the symptom of a passing jaundice which disappears in short order and is by no means alarming. All babies do not have it, but those that do, suffer no damage.

About the same time the child's skin begins to break up into fine scales and come off, and its hair-the fine down on its body and the longer hair which may have covered its head at birthbegins to fall out.

All of this shedding is quite normal, and is a mere preliminary to the appearance of the true, soft, satiny baby skin. With the beautiful texture of the latter every woman is familiar. It is nearly white on the body and limbs, but becomes a deep rose-pink on the palms and soles.

A healthy baby usually celebrates its advent into this wicked world by setting up a shrill cry. When this primal utterance is not heard, the doctor of ten provokes it by manipulating the newcomer's arms and legs, or even by treating it to a gentle spanking. This cry is a good sign, for it proves that the baby has sturdy lungs and that it has promptly discovered their use. But the absence or postponement of a wail need arouse no fears, for plenty of healthy babies greet the world with dignified silence. It is the firm belief of nearly all midwives that a child which cries feebly or not at all during its first few minutes of life is doomed to illness and early death. This belief is an heirloom from the age of portents and premonitions.

In this connection it may be of interest to note that a new-born baby, no matter how lustily it may signify its discontent, never sheds tears. This is because its lachrymal glands, like many of its lesser organs, have not yet found their function. Neither does it slobber, as babies of larger growth are apt to do, for its salivary glands are still inert, and its tongue, in consequence, is white and dry.

Loving mothers and imaginative aunts are wont to discover evidences of perception and intelligence during the first week, but as a matter of fact, a human infant, until it is fully a month old, is alive, and that is all. Its eyes may see, but its brain cannot understand, and all of its acts are automatic reflexes. Crying constitutes the primitive language whereby it makes known its few wants. It cries when it is hungry and when it is uncomfortable. The young mother will quickly grow familiar with its normal voice and so learn to detect variations.

A healthy baby cries about two hours a day for no other reason 
than that it needs exercise. This crying is not continuous, but is distributed over the twenty-four hours in short spells.

\section{QUESTIONS FOR THE MOTHER ABOUT CHAPTER II}

Should not the bringing up of a child strong in body and character require as systematic, careful and scientific study as any profession?

Yes. Enlightened mother-love learns the most advanced methods of caring for children.

How can the average mother get this knowledge?

In some large cities and small towns there are classes for young mothers with doctors held in the public schools or in the mothers' clubs. Many health departments send doctors or educational nurses to teach mothers in their homes the care of babies.

What should a mother do to belong to such a class?

She should ask her health commissioner or school superintendent whether he can direct her to such a class or send a teacher to her.

When should a mother put herself in the care of a doctor?

As soon as she knows a baby is coming to her. She should have a thorough physical examination and should consult her doctor frequently to prevent the dangers that often attend childbirth.

Should a mother go to a hospital for her confinement?

If the care of her home and children is heavy, she should do so. The rest and care of the hospital, as well as the education it will give her, is invaluable to her and to her baby.

What are the tests she should use in selecting her physician?

The best recommendation for a physician is that he is sought by his fellow physicians for advice.

What should she do if she is in doubt?

She should go to her health department and ask for advice in selecting the doctor to care for her and her baby.

Why should a mother never employ a midwife when she can go to a doctor?

Because many more babies who are brought into the world by midwives die than babies who are brought into the world by physicians. Because a midwife's education falls far below that of a physician. A woman should sacrifice her own prejudice, and always employ a physician. The best is not too good for her baby. 


\section{CHAPTER III.-BABY'S FIRST FEW MONTHS}

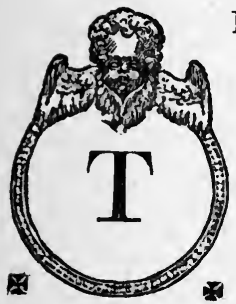

HE young child has almost no power of reason, but, like a little animal, it soon learns to make a sort of unconscious correlation between cause and effect. That is to say, it learns that certain acts lead to certain results. If its nurse or mother stills it once or twice by taking it in her arms, it will cry thereafter whenever it wants to be taken up. In the same way it will learn, in an incredibly short time, how to bring some one to its cradle-side to rock it. These cries of habit should be promptly suppressed, for, in the first place, it is not good for a child to be handled or rocked; and in the second place, compliance will quickly give it perverse and disagreeable habits. Let it cry for three nights in succession and it will hold its peace thereafter. The ancient fear that a baby which is permitted to yell away, without effort to soothe it and still it, will rupture itself, is groundless. A baby lying upon a soft pillow cannot possibly rupture itself, no matter how violently it cries or how vigorously it tosses about.

The cry of habit is much like the normal cry of every baby. The wails are long drawn out and have a sort of rising and falling cadence. They are still at once if the baby gets what it wants. If it does not, they gradually grow less loud and so cease.

The cry of pain, on the contrary, is a short, quick, gasping cry. The baby commonly draws up its legs and gives other evidences of serious disturbance. Mild colic, which is not dangerous, often produces this cry. Unless it is prolonged there is no need to be alarmed. The prudent nurse, however, will make a diligent search for tight napkins and loose pins.

The cry of hunger is a quick, sharp, staccato cry, with high, shrill notes, but less vigorous than the cry of pain. It should cease at once on feeding.

The cry of temper-and temper is exhibited by very young chil- 
dren-is long, sharp, and high-pitched. It indicates that the youngster is enraged - that it wants more light in the room, that its bed is uncomfortable, that it wants some one to change its position, or that it does not want the food forced upon it. Some children have such violent tempers that they throw back their heads and grow blue in the face and seem to cease breathing. The mother often fancies that they are in convulsions and sends for the doctor posthaste. The best way to deal with such recalcitrant little folks is to lay them in bed and let them cry. They will quickly observe the futility of their efforts and so cease.

When children grow older they acquire what might be called the "insulted " cry. A child of six months is sensitive to sharp words and gives voice to the humiliation they produce. This cry consists of a short sob, followed by a longer one, and slowly rising in volume, though not in pitch. Indeed, it is not unlike the cry of a woman.

The cries of pain, hunger and temper are accompanied by a drawing up of the legs. In the other cries the child's limbs have no part.

Babies change so much during their first few weeks that their appearance at birth gives no hint as to their future complexion, form or stature. One may come into the world with its mother's blue eyes and small nose, and attain its majority, twenty-one years later with the darker orbs and more formidable nose of its father. This is because nearly all babies have eyes of an indefinite, bluish color, and noses of no particular shape at all. The color of their hair, if they have any, is also misleading, for, as a general thing, it is considerably lighter than it will be in after years.

During its first month a baby has almost no control over its muscles. If you lay it down, it remains just where you put it and cannot change its position. If you hold it up, its head rolls about. In nursing, its movements are entirely automatic and unconsciousas much so, indeed, as those of the minute organisms which bridge the border-line between plants and animals. There is good reason to doubt, indeed, that it is conscious of pain. Its cry appears as a mere reflex and without the interposition of cognition or effort.

But this stage does not last long, for a baby grows with remarkable rapidity. The rate at which it lives is well demonstrated by observing the functioning of its organs. Its heart beats at a rate that would be fatal to an adult, and, as we have seen, it breathes very fast. At birth, for example, its pulse is often one hundred and for- 
ty-five a minute, which is just twice the normal rate in a grown man or woman. Its respiration is similarly hurried, being forty-five or more a minute for the first few weeks, as against sixteen to eighteen in the adult. The bowels of a new-born baby are usually very active, but the bladder may not function until after its first day.

By the time it is four months old the child weighs almost twice as much as it did at birth and is plainly making rapid progress. It can now hold up its head 'without support, and it has developed a habit of grasping any small objects which touch its hands. Before it is a month old it may smile, but it is not until some time later that its smile seems to be associated with any definite idea. But by the time it enters upon its fourth month its intelligence is fully dawning. It learns to recognize its mother, and ceases to cry when she takes it in her arms. Its eyes follow lights and moving objects and its ears detect noises.

Soon afterwards it begins to distinguish between its mother and other persons and to become fully conscious of the world about it.

A baby begins to utter sounds other than those of crying when very young, and before it is six months old it often acquires a vocabulary of three or four vowels. The first that it masters is commonly the broad " $a$," and this diligently repeated, as "ahah-ah-ah," convinces its mother that it has learned to say "mama." But, as a matter of fact, the youngster is merely voicing, with the one elementary sound at its command, its general feeling of comfort. This "ah-ah," indeed, is a brother to the purr of the house-cat upon the hearth-rug, and is similarly devoid of any underlying concept.

Soon, however, a multitude of crude but vastly interesting ideas throng the infantile brain, and the baby tries to talk. Some babies make such efforts as early as the ninth month, but others are much slower. The fact that a child is backward in talking is no sign of defective intelligence, nor does it prove that it will be a slow pupil later on. Some of the greatest men of genius the world has known were unable to form intelligible words until the age of two years.

In the matter of walking and teething there is the same unaccountable variation. Some babies are able to sit up at the age of six months and begin to make efforts to crawl at the same time. Held upright on its feet, a youngster of such precocity will try to stand erect, and will crow with delight if it succeeds. There 
are babies, equally intelligent and healthy, which seem to be hopelessly clumsy and are utterly unable to make the crudest approach to locomotion. As a general thing, a baby which begins to walk at sixteen months is doing well enough. Plenty of children try in vain until after they are two years old. If the baby's legs are strong and it is in good health there is no reason why backwardness in this respect should cause alarm. The various mechanical contrivances for teaching children to walk-rolling chairs, frames, etc. -are of questionable utility and may produce dangerous strains upon the weak bones and muscles.

\section{QUESTIONS FOR THE MOTHER ABOUT CHAPTER III}

What are some of the habits a young baby should be taught to form?

It should be nursed at regular intervals.

It should be fed, bathed, dressed and put to bed at the same hours each day.

It should be allowed to sleep most of the day and night except when it is time to be fed or to be bathed.

Is should be taught to eliminate its food at regular hours. There is no need for the disagreeable and unhealthy custom of soiled diapers. If you hold the child on its little "chair" once an hour, you will help it form clean habits that will prevent constipation.

Need a baby always wear flannel next the skin?

A baby should be dressed according to the weather. It should never be allowed to get chilled. It should neve: be allowed to get into a perspiration, for its body is apt to become chilled. A baby's little body will become chilled or heated quicker than an adult's. Keep its hands and feet warm in winter and dress it very lightly in summer.

Should a baby wear long clothes?

If it is born in the cold weather, it may wear long clothes for the first few months, but they must not be long enough to be heavy and drag on the child's shoulders. If it is born in the warm weather, it should wear dresses not below its feet.

What should a mother remember about her baby's clothes?

She should put herself in the baby's place. She should remember that its skin is very tender and that buttons, pins, wrinkles hurt it, make it restless, uncomfortable and fretful. 


\section{CHAPTER IV.-THE NURSING BABY}

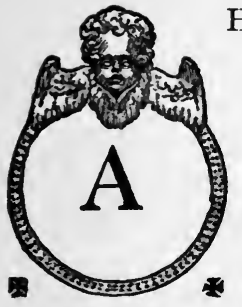

HUMAN infant, during the first few months of its life, is an extremely delicate organism, and so it should be handled with care, which means that it should be handled as seldom as possible. The young mother who, in the excess of her pride and love, cuddles her baby to her breast and showers kisses upon it by the halfhour makes a pretty picture, it must be admitted, but it cannot be maintained that the little one is benefited by her caresses. Quite to the contrary, her every kiss helps to make it nervous and irritable and prepares the way for the seeds of disease. A baby that is fondled too much is a baby that cries too much, and is ill too much.

Despite the evidences of intelligence apparent to loving eyes after the first week, an infant's mind is a happy blank, and it gets no joy out of the affections. To it, its mother appears merely as a source of food, and later on, when its brain begins to function, this primitive association of a craving and the means of satisfaction is probably the first definite idea that formulates in its mind. When it is hungry, it wants its mother to feed it, and before long, instead of merely crying for food, it cries for her.

When it is not hungry, its chief need and desire is for sleep. A healthy baby, during its first month, should sleep at least eighteen hours a day. And this sleeping should be done, not in a rocking, nerve-racking cradle, but in a solid, comfortable crib. The cradle belongs to the age of spinning-wheels and flails, of soothing syrups and necromancy.

It is not until the fourth day after the baby's birth that its mother's milk is truly nourishing, but such as it is, it exactly meets the needs of the child. It is, in fact, a sort of laxative serum, which stimulates the entire digestive tract and prepares the stomach for the reception of food. On the first day the baby should be nursed only once, but it should be given a drink of boiled water every three 
hours or so. On the second day it should be nursed three timesmorning, afternoon and night-with the same allowance of water. On the third day the routine of the second day should be repeated. At the end of the third day it will be found that the child has lost a quarter or half a pound. This need cause no alarm, for it is perfectly natural, and a steady gain will immediately begin.

On the fourth day both baby and mother are ready for regular feedings at shorter intervals. From this time onward, until toward the end of its second month, the child should be nursed every two hours, with a slightly longer wait after its daily bath, and an interval of seven hours in the night. In all, it should have about nine feedings during the twenty-four hours, as follows: 6,8 and 10 A. M. and 1, 3, 5, 7, 9 and 11 P. M. Between eleven o'clock in the evening and six in the morning it should not be fed at all. The fact that most babies demand food during this time merely shows that most babies have bad habits. Let the child cry in vain for three nights running and it will never cry again. But during the day, even if it happens to be sound asleep, it is well to waken it in order to keep to this schedule faithfully.

The bath should be given just before the ten o'clock feeding in the morning. The water should be at the temperature of the bodyabout 99 degrees - and soap should be used very. sparingly. After the child has been gently washed, sponge it with a soft cloth dipped in cold water and give it a brief rub-down with alcohol. This will bring the blood to the surface, stimulate the circulation and prevent colds. It is well to let the baby sleep three or four hours after its bath. Then, if it has not already awakened and demanded food, it should be aroused and the regular schedule of feeding resumed.

The length of time that the child should be kept at the breast at each feeding depends so much upon the volume of the milk and its own idiosyncrasies that it is impossible to lay down an invariable rule. The mother should be guided by the fact that a newly-born infant's stomach has a capacity of but one ounce, or eight teaspoonfuls. Some babies are able to ingest this amount of milk in a few minutes, while others require much longer. But it is rarely safe to keep a child at the breast for more than from ten to fifteen minutes.

An infant's stomach is not a fully developed organ, and, as every one knows, it can digest only milk, or something closely approximating milk in composition. As a matter of fact, it probably plays 
but a minor rôle even in the digestion of milk, for it stands almost perpendicular and is really little more than an extension of the bowels. The food which enters it passes into the bowels very quickly, and there the more important part of the process of digestion takes place. But, all the same, a baby should be given no more food than its stomach can hold.

A baby, like an adult, needs water as regularly as it needs food. The milk that it gets, though a liquid, does not satisfy its thirst. It should be given water at least three times a day, and this water should be nearly, if not quite, free of organisms. The water that comes from the average city main or country spring is alive with microscopic plants and animals, even when it seems clear and sparkling. These minute organisms, as a rule, are harmless to adults, but in the delicate stomach of the baby they are apt to cause disturbances, and so they must be eliminated. The best way to get rid of them is to allow the water to boil twenty minutes. After that, let it cool and store it in clean, well-corked bottles which have been previously immersed in boiling water for five minutes. Glass stoppers are better than corks.

Boiled water is tasteless and insipid because of the absence of air-bubbles, but the baby seldom notices it. It is best drunk out of a thoroughly clean nursing-bottle. Offer water to the infant every four hours, and let it drink as much as it wants. The supply for each day should be boiled in the morning. Under no circumstances should water be kept more than a day.

\section{QUESTIONS FOR THE MOTHER ABOUT CHAPTER IV}

\section{Who should kiss your baby?}

Nobody should kiss it on the mouth, not even you. You should instruct every one who is likely to come in contact with it to kiss it on its cheek or forehead. Instruct your nurse not to let strangers kiss the baby. A consumptive's kiss might give it tuberculosis.

How much should your baby sleep?

A healthy infant should sleep most of the time except feeding time.

Should any attempt be made to develop a young baby's mind?

No. A baby should not even be played with, or in any way excited. This makes it nervous and gives it indigestion. Remember, much joy as your baby gives you, it should never be made 
to give you, your family, or friends, entertainment at the sacrifice of its own health and regular habits.

How should $a$ baby be put to bed in the day time?

A baby should always sleep alone. It must have a little bed of its own. Not a cradle, but a crib with a flat mattress and a low pillow or no pillow. The baby should be put to sleep on a shaded piazza, or yard, or in a room with the windows open. Its covers should be suited to the temperature of the day. It should never be allowed to become chilled or to perspire. In cold weather the sun should shine on its bed but never in the child's eyes.

What is meant by being "regular" with the baby?

That it should be fed at the same hours every day-bathed at the same hour every day-put to sleep at the same hour and taken up at the same hour. That its bowels should move at the same hours - that it should not be fed whenever it cries--not to be taken up to entertain visitors - that it should be expected to sleep all night without feeding or petting.

How often should the baby be bathed?

The baby should be bathed every day before the ten o'clock feeding. Everything necessary to the bath should be in readiness before the baby is undressed. Hang up a list of the necessary articles in the bathroom and consult it every day. The baby may get chilled while you are hunting up something you have forgotten.

\section{LIST}

Tub-warm water-bath-room thermometer-soap-gauzecotton wads in covered glass-powder-vaseline-flannel apron towel-gauze towels-clean clothes and diaper-alcohol. Solution of boracic acid in covered glass.

How should the bath be given?

Let the room be thoroughly warm before you undress the baby. Be sure there is no cold air on its little body.

Wash the baby's eyes and mouth with a swab of aseptic cotton dipped in a weak solution of boracic acid. Wind up a little wad of cotton and clean its ears. Dip a wad of cotton in vaseline to cleanse its nose. Never stick anything hard into a child's ears or nose, and be careful not to leave any cotton in the ears or nose. A baby's membranes are very easily injured.

Then put the child into a tub of warm water and wash it all over with a mild soap. Teach the baby to enjoy the bath. Let it splash 
about and have fun. It will save you much trouble. Never prolong the bath to please the baby or to entertain friends. Do not let people go in and out of the room while the baby is undressed. Use for a wash rag a piece of aseptic gauze, or bleached cheese cloth, boiled. A sponge catches and develops germs. It is unclean as it cannot be boiled without ruining it. Complete the bath with all dispatch. Wrap the baby in a woolen blanket to absorb the moisture quickly. Powder it with soft powder, dress it and feed it and put it at once to sleep in the air. 


\section{CHAPTER V.-MOTHER AND BABY}

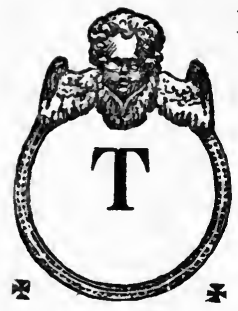

HE nursing-bottle and nipple, whether used for water or for artificial food, should be immersed in boiling water for at least five minutes every day, and when they are not in use they should be kept in a covered glass filled with a weak solution of boracic acid. Such a solution is of constant usefulness in the nursery, and it is well to prepare it in bulk. A cupful of boracic acid, to be had at any drug store, will suffice for two gallons of water. Keep it well covered and it will last for a long while. Use it to wash all dishes, cups, bottles, spoons and other utensils that play a part in the baby's commissariat.

The best possible food for a baby is mother's milk, and this is what it should get whenever possible. The mother who permits social "duties," laziness or any other such excuse or motive to interfere with her highest of privileges is a woman unfit to bring human beings into the world. The best of all infant foods, like the best of all varieties of modified cow's milk, is but a sorry substitute for mother's milk. Nothing devised by the ingenuity of physicians and chemists can so perfectly combine the offices of food, drink and medicine as does this natural food.

When I say medicine, I speak literally, for mother's milk gives to the baby some measure of her own acquired power of resistance to disease. There is, indeed, good ground for the old saying that, so long as a child is at the breast, the blood of its mother continues to flow through its veins. Recent investigation in susceptibility and immunity have shown that this is true, at least in effect, for the breast-fed child shows a distinctly greater capacity for resisting the organisms of all the principal infectious diseases than the child fed upon artificial food. To put it simply, the baby nursed by its mother is far less likely to take measles, scarlet fever or chicken-pox, and far more likely to recover quickly and completely if it does, than the baby nourished by cow's milk and cereals. 
Unfortunately, contingencies sometimes arise which make it unwise or impossible for the mother to nurse her child. It may happen, for instance, that the former is suffering from some infectious disease, such as tuberculosis. Under such circunistances, nursing is out of the question, for, besides its dangerous effect upon the health of the mother, it is also apt to bring disaster to the baby.

The child of a consumptive mother should be taken from her at once and brought up away from her. She has a battle for life ahead of her which will consume all of her available energies, and the child, too, has a serious but not hopeless battle against inherited predisposition. An infant is ill-fitted to breathe the air of a consumptive's sick-room, and an impulsive kiss may doom it to long suffering - with "spine disease," for example, a frequent form of tuberculosis in children-and an early death.

Any other sort of serious illness is sufficient ground for weaning the child at once. There are also other conditions which make it impossible, however good her intentions, for a mother to nurse her child.

Even while she is nursing her child, some physical or mental disturbance may interfere, temporarily, with a mother's supply of milk. Household cares are often responsible for these difficulties, which show themselves in a scanty supply or in illness in the child. The mother who has half a dozen other children to care for and a house to look after is not capable of providing her baby with the nourishment it needs. During the nursing period she should be relieved as much as possible of domestic cares. Needless to say, she should avoid all excitement of whatever sort. Giving a dinnerparty is almost as costly to her strength as a fit of passion or a severe fright, and either may cause the supply of milk to cease or render it unfit for the baby's stomach. Severe intestinal disturbances in nursing children are often caused by maternal imprudences.

The nursing mother should eat plenty of simple, nourishing food, and avoid all stimulants. Alcohol, in particular, is to be held in abomination. She should eat meat sparingly, and should make eggs and vegetables her chief articles of diet. Let her drink milk freely, and avoid coffee and tea. Of raw fruit she had better be wary, but plenty of cooked fruit will help to keep her well. Needless to say, she must pay quick heed to all minor illnesses, particularly disturbances in the digestive tract.

Young mothers are prone to take an unsafe pride in getting 
about as soon as possible after their babics are born. This ambition, it is plain, deserves no encouragement. The average American woman, especially in the large cities, is far from perfect physically, and so it is well for her to be extremely prudent. But at the end of three weeks it is usually safe for her to take a short drive or shorter walk. As her strength grows she should begin regular daily exercise, preferably walking. Let her keep the windows of her room open, and remain in the open air as much as possible. She needs eight hours of sleep in the twenty-four, at the very least.

When it becomes impossible for a mother to nurse her child, two courses are open: either the baby may be handed over to a wet-nurse, or some effort may be made to nourish it with artificial foods or modified cow's milk.

Wet-nurses, at their best, are unsatisfactory, and at their worst they are exceedingly dangerous. One of them may submit herself to the scrutiny of careful physicians and pass them as perfectly sound, and yet be suffering, all the while, from a communicable malady. Taken as a class, they are ignorant, careless and unclean. Setting aside the cocasional gem among them, they seldom provide their charges with nourishment as wholesome as that to be had from the milk laboratory.

\section{QUESTIONS FOR THE MOTHER ABOUT CHAPTER V}

\section{What should a baby be fed?}

For the first few months, its mother's milk is the only food that should be given to the baby.

The baby should have water three times a day, every four hours, between feedings. It should be boiled and cooled and given in a nursing bottle that has been boiled, or with a spoon.

How can a mother keep her milk in good condition so that it will nourish the baby?

She should eat three plain well-cooked meals a day at regular hours. She should drink water between meals. Keep her bowels regular-constipation in a nursing mother often causes colic in her baby. The baby's health is dependent upon the mother's health. Often when it seems as if the baby must be put on artificial food, by building up the mother's health her milk is improved and the baby thrives on it. 
What may make a mother's milk poor?

Lack of rest and nervousness. Not enough nourishing food. Constipation.

What is the mistake most mothers of young babies make?

They try to do too much. They should stay in bed at least three weeks after the birth of a baby, and should cultivate the habit of resting as much as possible before the birth and during the nursing period.! It should be a happy, restful time when sleep, food and exercise are abundant. To make it so is the duty of a mother. It is far more important for the future of her family than are the many things she wears out her strength doing.

Why is nursing so essential to a baby's future health?

Because mother's milk is the natural food. It gives the child the immunity of its parent. It aids the mother by reflexly strengthening her internal organs. A child will grow and thrive on cow's milk, but it has twice as many chances to reach maturity when breast-fed. 


\section{CHAPTER VI.-THE BOTTLE-FED BABY}

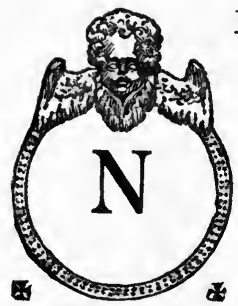

EXT to mother's milk, the best of all available foods for human infants is cow's milk. I say "best," but in this connection the word is almost meaningless, for the difference between mother's milk and cow's milk is great. The first is at once a perfect food and an efficient medicine, while the second is a very unsatisfactory food and no medicine at all. That is why a child fed at the breast, all other things being equal, has just about twice as many chances of growing up healthy and sturdy as a child fed from a bottle. Bottle food, no matter how carefully it may be prepared, is a mere substitute and, like all substitutes, it is likely to be dangerous.

The chief superiority of mother's milk lies in the fact that it contains all of the nutritive elements needed by the baby, in precisely the right proportions-and nothing else. It is easy enough to prepare an artificial food that contains one or more of these elements, but no man has yet invented one that contains all of them. Again, it is impossible to rid artificial foods of certain things whose presence in the infantile digestive tract causes trouble. Some of these things are merely superfluous, but others are often indistinguishable from poisons.

Saving only the milk sugars and the water, not one of the important constituents of mother's milk is exactly duplicated in cow's milk. Consider, for instance, the difference between the caseins of the two. To understand it, one must remember that a casein is made up of proteids and that proteids constitute the most important of all elements of human nourishment. The albumen found in the white of an egg is a proteid, and the lean part of meat is heavy with proteids.

Well, all proteids, when they reach the stomach, begin to clot, just as the albumen in an egg coagulates when the egg is heated. The proteids in mother's milk and in cow's milk clot in just this 
way, but what a difference in the manner of their clotting! Those of mother's milk clot into fine flakes, which remain separate and are easily attacked by the secretions of the baby's stomach, and so start at once upon their metamorphosis into blood. But those of cow's milk clot into large, tough lumps, with which the baby's stomach struggles in vain.

The result is that mother's milk is digested easily and rapidly, while cow's milk is digested only with difficulty, and sometimes not at all. This fact explains the frequent colics, vomiting, diarrhea and other forms of indigestion.

Again, cow's milk contains nearly three times as much casein, proportionately, as mother's milk, and in consequence the child who ingests it undiluted is overfed. This helps to burden the harassed stomach and makes the disorder more violent and more frequent.

There are similar differences between all the other constituents of mother's milk and cow's milk, particularly the acids, but they are understandable only to physicians and chemists. More apparent and more important is the fact that cow's milk, as it is received from the dairyman, is alive with a multitude of germs that are never found in mother's milk. There is no doubt that, if the latter were stored in vessels and transported long distances before being fed to babies, it would be just as bad, but every one knows that it is never so stored and transported. It reaches the baby's stomach warm and fresh and without exposure to the air, and so it is always clean and pure.

When a cow is milked the milk takes up floating germs from the air through which it passes in its descent to the can, just as the rain-drops of a Summer shower take up "the gay motes that dance along a sunbeam." These germs, finding the milk a fertile soil, begin to multiply at once and with enormous rapidity. According to some observers, the process begins within thirty seconds. If the can is unclean, or has been washed with contaminated water, if the milkman has dirty hands, or if the cow itself is infected with tuberculosis or any other infectious disease, other and more virulent germs reënforce those of the air, and before long the innocentappearing can of fresh milk is swarming with organisms.

It is impossible to stamp out these germs entirely, but proper handling of the milk greatly reduces their number. This proper handling looks to two things - a constant low temperature, and 
absolute cleanliness. The milk must be cooled, and it must be kept cool until it is used. Again, it must be transported, not in open cans, but in air-tight bottles. In practically every American city milk is sold in just such bottles.

Once free of germs, or reasonably so, cow's milk is still unfit to be fed to the baby, for its proteids, sugar, fats and acids are yet present in improper proportions. It has, for instance, certain strange acids, and these must be neutralized.

I desire to impress upon all mothers, the desirability of seeking advice from a good physician whenever it becomes necessary to take the baby from the breast. Only a doctor can accurately determine the needs of a given child.

In most cities there are milk laboratories which make a business of modifying cow's milk upon prescription. The physician, knowing the child's peculiar requirements, decides just how much casein, sugar and fats should enter into each quart of milk that it ingests, and the laboratory prepares a milk containing these things in exactly the right proportions. Such milk may be prepared at home by the mother under a physician's direction.

Until it is six months old the bottle-fed baby should take nothing but modified milk and boiled water into its stomach. It should be fed according to the schedule I have laid down for breast-fed children, and should get just as much water. The strength of the modified milk should be increased from month to month. During the first few weeks it may be advisable to use four, five or even six parts of water to one of milk, but after the first month the proportion of milk may be increased in amount quite rapidly. By the end of the second month, if the baby seems to be thriving, it may take equal parts of milk and water, and later on the milk may exceed the water until, toward the end of the first year, the child may take almost pure milk. But this should be managed with caution, and at the first sign of digestive disturbance there should be a wise retreat.

When the first teeth appear it is time to add something more substantial to the diet. Many physicians condemn baby foods without reservation, but in this I cannot concur. Wisely employed, they are often of great value, but it is not wise to use them unless absolutely necessary, and then only in selected instances. I often, but not always, add them cautiously to the milk, beginning with very little milk, then, if all goes well, gradually increase the proportion. Such foods should not be used save in such conjunc- 
tion with milk. In selecting a food it is well to remember that the advice of your doctor is far more valuable than that of your neighbor, for babies differ.

By the time the baby is a year old its diet should begin to include fruit juices and the whites of eggs. Begin with a wine-glass of chicken broth or bouillon, fed from a spoon, and as these things are increased, gradually decrease the amount of bottle food. Soon after it turns its first year the child should learn to drink from a small cup. After that its meals may be reduced to five a day, with an occasional drink of orange juice and plenty of water.

The first meal should have modified milk as its chief constituent, with half as much infant food or strained oatmeal added. The second meal, in the middle of the morning, may be a repetition of the first. Early in the afternoon a gill of chicken broth, or half as much beef juice, may be given, and this may be varied every few days, with the white of an egg boiled, say, for a minute. The two remaining meals should have milk as their mainstay. After a month or so of such diet, if the baby is in good health, its mid-morning meal may begin to include dry toast, zwieback, thin oatmeal and other cereals, and its afternoon dinner may include a whole egg, soft-boiled or poached. Fruits should be given freely, but it is always best to have them well cooked.

I need scarcely refer again to the need for keeping all bottles, nipples, glasses and spoons absolutely clean. They should be scalded after each meal, and should be kept, between meals, in a vessel filled with a dilute solution of boracic acid. Just before using they should be washed thoroughly in very hot water. Particular attention must be paid to the rubber nipples. They are veritable havens for wandering germs.

\section{QUESTIONS FOR THE MOTHER ABOUT CHAPTER VI}

Why is it that so many more bottle-fed babies get sick and die than breast-fed babies?

Babies often have diarrhea and vomit because the milk is not clean-has not been kept cold-has been kept too long-is not properly prepared or the nursing bottles and nipples are dirty.

How can a mother avoid the danger that comes to babies through cow's milk? 
She should consult a doctor that knows about babies, and find out if she can not nurse the child. If not, she should get from her doctor a prescription for preparing the milk to suit her baby's stomach. She should weigh her baby on the same scales once a week, and if she finds the child losing weight or not gaining for several weeks, she should consult her doctor again and ask that the formula be changed.

What is the best and easiest way to prepare the milk?

The milk should be prepared every morning for the day's supply. It should be put into the feeding bottles and corked with aseptic cotton and put on the ice. Each bottle should be warmed by putting the bottle in hot water just before giving it to the baby.

The bottles should be boiled just before filling with the day's milk.

Throw away what the baby leaves. Never give the left over milk to it for another feeding.

As soon as the bottle used by the baby is empty, it should be thoroughly washed with cold water-then cleansed with borax and hot water (one teaspoonful of borax to a pint of water). The nipple should be thoroughly washed after each nursing with hot water and when not in use should soak in boric water in a covered glass. The nipple must be rinsed in boiling water just before the baby uses it. Bottles and nipples should be boiled once a day.

Why need such extreme care be taken to sterilize bottles and nipples before giving them to the baby?

Because milk is one of the best "culture" mediums. Germs develop in milk with incredible rapidity. Therefore you may often be giving poison to your baby when you think you are giving it clean, nourishing milk.

What should a mother do if her baby has diarrhea?

She should stop all food at once-give cool boiled water, no medicine. Take the baby to a doctor at once. It is dangerous to wait, especially in summer.

What causes diarrhea?

Diarrhea comes from too much food-too frequent feedingtoo little water-too little sleep-too much handling-too little air, and from milk that is dirty or has not been kept on ice.

Why does a child vomit and have diarrhea?

Because some food that it cannot digest, some sour or dirty milk has been taken into its stomach, and it vomits and has diarrhea because it is trying to get rid of the food that is making it sick. 
Why does diarrhea come to babies in summer?

Because in summer milk gets warm, and germs and poisons multiply.

Why do more bottle-fed than breast-fed babies have diarrhea?

Because cow's milk is less likely to be pure and suited to the baby's stomach than mother's milk.

How can a mother prevent diarrhea?

By taking a baby to her doctor to be sure its food is right before hot weather sets in-by keeping it out in the fresh air, bathing it daily and sponging it with cool water on hot days-by keeping it quiet and letting it have plenty of sleep. Thus its body will be able to resist disease. 


\section{CHAPTER VII.-A CHAPTER ON MILK}

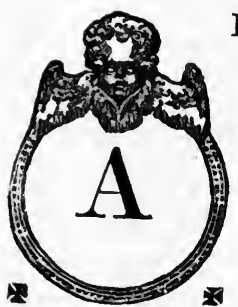

FTER all, those socialists who insist that the bread-and-butter problem is the one all-inclusive human problem are not very far from right. A man's mental, moral and physical make-up depends, to a degree incredible to the casual observer, upon the food he eats, and, to a degree still more incredible, upon the food he ate when he was a baby. Save only the air he breathes, nothing more potently determines the sort of man he is to be- not even his nationality or his faith.

Of course, it is impossible to find out, with any approach to exactness, the eventual effect of a given food-stuff, but every one is well aware of the peculiar emotional consequences which arise out of certain general conditions of diet. The starving man has no conscience, and the dyspeptic has no soul. At the other pole stands the well-fed man of sound stomach. He is as happy after dinner as any human being can ever hope to be.

Between these two extremes one may find a thousand other proofs, physical, and psychical, of the effect of food upon the human animal. It is, indeed, fast becoming a favorite theory among biologists that many of those changes which cause the evolution of species are due to changes in nutrition; and there is even some ground for believing that man's enormous superiority over all other beings to-day is due in part to the fact that his remote ancestors, one lucky day, discovered the art of cookery.

Nature provides the best of all possible foods for babies in mother's milk, but accidents often make this unavailable, and so it becomes necessary to seek a substitute. This substitute has almost invariably been the milk of the cow, the goat, the reindeer, the horse or the eamel. Until recently it was generally believed that the substitute was as good as the thing it supplanted. But one day there appeared a man named Louis Pasteur, who showed the world that cow's milk, to name but one of these substitutes, was always 
a dangerous food, and that, in a great many cases, it was a violent and fatal poison.

Pasteur proved this by his discovery that cow's milk, by the time it reaches the nursery, always contains microscopic forms of life. Some of these minute organisms, perhaps, are harmless enough, but others are the very reverse. So noxious are they, in fact, that it is fair to blame them for a large proportion of the maladies of childhood, and, in addition, for not a few of those defects of bodily function which, while not at once fatal, pave the way for illness and death later on-perhaps as late as middle life. .

The layman may here want to know why it is that cow's milk, if it is so badly contaminated, does not poison the calves for whom nature intended it; and why, again, if cow's milk is so dangerous, mother's milk is not just as bad. The answer lies in the fact that, when any milk is fed to the offspring of its mother in the way nature intended it to be fed, it does not come in contact with dirt.

A bacteriologist named Soxhlet, in 1882, finding that a certain degree of heat would kill germs proposed a simple method of heating milk, and it was believed for a time that the problem was solved. During the next twenty years, however, with sterilization widely practised, the death-rate among infants declined very little.

Then it was discovered that heating the milk, while it killed the germs, caused changes in the proteids, salts, fats and other constituents, and that the products of such changes were often dangerous. It was also found that the constituents of cow's milk differ vastly from those of mother's milk, and that some of them in their natural state are poisonous to human infants. The result was an effort to change these constituents in such a way that they would more closely resemble the corresponding constituents of mother's milk. This effort is still in progress, and its visible fruit is the large. number of "modified" milks now offered. Some of these are excellent, and, if properly administered, almost all of them do more good than harm, but we are still far from a modified cow's milk which exactly duplicates mother's milk. This is proved by the fact that, despite the progress made, the death-rate among bottle-fed babies exceeds by far that among babies fed at the breast. Both have declined enormously in the past twenty years, but that decline is due, not so much to improvements in food as to improvements in the prevention and treatment of contaminated milk and the diseases it produces. 
A gigantic hoard of ancient fallacies and superstitions clusters about the nursing mother. There are a thousand signs, and portents which command immediate weaning, and I suspect that, in the case of many of them, the wish is father to the too-ready belief. All sorts of slight indispositions are seized upon as excuses for condemning the baby to the bottle-a trifling cold, a temporary reduction in the quantity of milk, a day or two of poor appetite, a headache, even a toothache. "That tired feeling," accompanied by irregularities in the milk-supply, is often the effect of a night at the theatre, a game of bridge or an attempt at heavy housework. The nursing mother must take good care of herself, she must keep early hours, get plenty of sleep and food, and avoid all emotional excitement, but she is by no means an invalid, and those slight aches and illnesses which afflict all of us incessantly do not afford her a sound reason for neglecting her sacred obligation to her child and to the human race. I have succeeded in bringing milk back into women's breasts who had not nursed the child for three months.

It is commonly believed that if the nursing mother, for some minor indisposition, takes a drug of any sort, it will appear in the milk and injure the child. In the main, this is not true. Very few drugs do this, and it is easy for the mother to avoid those. Among them are codein, salicylic acid and mercury. The last is not frequently prescribed, but the first is contained in many patent "headache cures," and the second is often used to preserve canned foods. It is easy enough to avoid "headache powders" and it is easy, too, to avoid canned foods. Even in case the latter are eaten, it is possible to avoid those which contain salicylic acid, for the presence of this drug, thanks to the new pure food law, must now be announced upon the label.

The nursing mother would better eschew all stimulants, but if she has been in the habit of drinking, say, a glass of beer a day, there is no reason why she should stop it during the nursing period. I am no apologist for alcohol, but it is an undoubted fact that those who are habituated to it, in small quantities, suffer discomfort on abandoning its use, and this discomfort may imperil the milk-supply far more than the alcohol itself.

The old notion that a bottle of beer, ale or porter a day benefits mother and child by "strengthening" the former and increasing the supply of milk is an utterly nonsensical superstition. Far from be- 
ing strengthening, beer is the very reverse, and ale and porter, having more alcohol in them, are even worse. Therefore, it is dangerous for any woman to begin their use during the nursing period, but, all the same, it is inadvisable for a woman who has grown accustomed to them to abandon them suddenly.

The same thing may be said of tea and coffee. The woman who has looked forward daily to her afternoon cup of tea can not forswear it without discomfort, and this emotional storm may easily interfere with the milk-supply. Such a woman needs her cup of tea as much as a smoker needs his after-dinner cigar. As every one knows, the smoker who tries to stop smoking suddenly often suffers agonies which bring him to the verge of an actual nervous breakdown.

But in all such matters it is wise to exercise great moderation. Beer, tea and coffee must ever be regarded not as necessary foods, but as necessary evils. The woman who employs stimulants to enable her to perform the double task of nursing a baby and doing heavy housework, is very short-sighted, to say the least. Within a short time the penalty will have to be paid-and the poor baby, unluckily, will have to pay most of it.

Best of all stimulants and auxiliaries for nursing mothers is clean, fresh cow's milk. An adult woman, in most cases, is able to digest it without discomfort. Its nourishing constituents will give her healthy blood and general well-being, and these boons she will pass on to her child. This is the best of all methods of modifying cow's milk for infant consumption, and the wizards of the laboratory will never produce anything to equal it.

\section{QUESTIONS FOR THE MOTHER ABOUT CHAPTER VII}

Why is mother's milk better for young babies than cow's milk?

Nature has put all the elements necessary to nourish and develop the baby in the milk of a healthy mother.

Why must cow's milk be modified for babies?

It must be made as nearly as possible like mother's milk.

Why will not the same formula do for all babies?

Each mother's milk is different, suited to the particular needs of her baby. No two babies' stomachs are exactly alike. Therefore, the doctor makes an analysis of a mother's milk to find out 
just how to prepare the artificial food for her baby. Often when he finds out what is lacking in the mother's milk, he can, by special diet in the matter, rectify her milk or supplement the absent ingredients by giving the baby one bottle-feeding a day.

Why must the baby's formula be frequently changed?

Because the baby's stomach develops and requires different ingredients to continue the development. Nature varies mother's milk to suit the baby's developing stomach.

Why is pasteurized milk often recommended for babies?

Because many bacteriologists believe that pasteurization kills the germs in milk that make babies sick.

What is pasteurization?

It is raising milk to a temperature of from 140 to 167 degrees Fahrenheit and keeping it at that temperature for from 20 to 30 minutes.

How is it that pasteurization does not kill the germs in milk that nourish the "favorable" germs?

There is no reason to believe that it does not. Does this not work an injury to the baby? Many physicians believe that it does. Many also believe that this is a lesser evil than impure milk.

Is there no way of procuring raw milk, that is safe?

Yes, milk that is carefully and intelligently produced is safe for the baby to take raw if properly modified.

How may a mother know if raw milk is safe?

She may have her board of health make frequent bacteriological tests of the milk coming from the dairy. She may visit the farm and inspect the methods of producing milk.

What are some of the things up-to-date dairymen do to protect milk? They keep the cows in a well-aired, clean smelling cow-barn. They feed cows clean, good food. They have their men wear clean white milking suits. They have the cows' bellies and udders washed in disinfectant and the men wash their hands in disinfectant before milking. They have all bottles thoroughly sterilized. They have milk immediately cooled and kept at 50 degrees Fahrenheit until it reaches the consumer.

Does not this increase the cost of producing milk?

Yes, every mother should be willing to pay extra to have the best milk. Milk that is fit for babies cannot be produced under 8 cents a quart. Beware of 5 cent milk. Beware of "loose" milk. 
Is not 10 or 15 cents a quart for milk for your baby cheaper than letting it get sick and perhaps die?

Yes, you pay it not only for your baby but for all babies. Every time a mother buys cheap milk she makes it harder for dairymen to produce, good, clean milk. The realization of this fact by mothers will do more than any other thing to secure a universally safe milk supply.

Must milk be always kept at 50 degrees Fahrenheit?

Yes. It is better to get a small supply twice a day if you have no ice. A small piece of ice in water will keep milk bottles cold all day and sometimes longer. If you cannot get ice wrap a cloth wrung out in cold water around the milk bottle. Always keep milk covered. If you know that the milk has been warmer than $50^{\circ} \mathrm{F}$. for long, then boil it before using it. 


\section{CHAPTER VIII.-THE FOOD FOR GROWING CHILDREN}

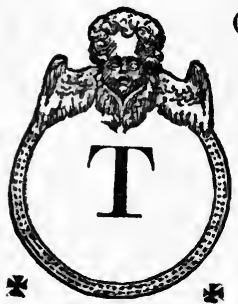

OWARD the end of the first year a human infant begins to be the most interesting thing in the world. Heretofore it has lived a life of colorless, unconscious, vegetative growth; and though its mother, perhaps, has discerned a meaning and a portent in its every sign, its actions, in sober truth, have been chiefly reactions, and, as such, have sadly lacked motive and coherence. But now its intelligence is dawning and the mysterious something that we call personality is unfolding. It begins to differ from other babies of its age in a thousand surprising and delightful ways; it acquires habits, appetites, little vanities, likes and dislikes, and what may be called a customary attitude of mind. And these things appear, one after the other, with truly dazzling rapidity. Every week sees noticeable progress. Every day has its perceptible change.

Mind and body join in the metamorphosis. Muscular and organic activity increases, and a multitude of ideas-nebulous, maybe, but still vastly engaging-begin to throng the child's brain. It begins to take note of the world about it; to recognize differences; to observe cause and effect; to put fact and fact together. And with all this awakening from within there comes a need of changes without.

As every woman knows, the time for weaning commonly brings perils for the infant. That this is the rule is shown by the fact that popular lore has given it the dignity of an immutable law of nature. As a matter of fact, there is no reason whatever why weaning should bring serious consequences to either mother or child, for it is as thoroughly normal an incident of life as birth or teething. In practically all cases the disasters of this period are due to an inaccurate reading of the baby's needs.

Many mothers believe that a prolongation of nursing is beneficial to the child, but this is not true. The baby fed upon milk exclusively beyond the normal time is usually a weak and anemic child, 
whose external appearance gives evidence of the retarded development of its organs of assimilation.

Until it is well on toward its second birthday, the principal food of every child should be milk, but this milk needs reënforcement. Let one meal be of modified cow's milk alone, and the next of milk and toast, with milk next and then a bit of mashed potato, and so on.

In this connection, and before proceeding to a consideration of the diet later on, it may be well to point out that the dietary needs of every child are determined more by its weight than by its age. An average baby, weighing about eight pounds at birth, should weigh about seventeen pounds at the age of nine months, when it is ready to be weaned. If it weighs less than this, it is well to seek medical advice before making changes in its food.

The same factor determines the amount of food required by the child each day. A normal baby of twelve months, weighing twentyone pounds, will need five feedings of modified cow's milk, of eight ounces each and at intervals of four hours, in addition to the alternate meals of toast, rice, and so on. But if the child weighs but sixteen or seventeen pounds, six or seven ounces of milk will be sufficient. By the same token, if it weighs more than twenty-one pounds, it may well take a bit more than eight ounces.

Once the milk of early infancy has been reënforced by the starchy foods, and the child has passed the Rubicon in safety, it is in order to reduce the former, by slow stages, to second place. As soon as possible teach the child to drink from a cup and give it its daily milk in that way. Reduce its allowance of milk to four eightounce rations a day, and at the same time add a meal of beef-juice or mutton-broth with a soft-boiled or poached egg. By the time the child is a year and a half old, broiled and scraped steak may be substituted for the broths.

To prepare this sear a round steak, on the outside only, over a brisk fire and scrape it into a fine pulp with a knife. Take about two tablespoonfuls of this and mix it thoroughly with an equal amount of stale bread-crumbs. Then let the baby eat it with a spoon.

Toward the end of the second year it is time to abandon the schedule of meals I have given in a previous chapter, and to progress, by degrees, toward three a day. Begin by omitting the meal of milk taken just before bedtime and gradually increase the importance of the midday dinner. By this time the baby will begin 
to show dietetic likes and dislikes, and, within reason, these should be taken into consideration, for a child, like a grown person, thrives much better upon dishes it relishes.

Let breakfast consist of a cereal with plenty of milk but little sugar, and a single egg, either soft-boiled or poached. As every onc knows, the American market affords an infinite array of palatable cereals, and the great majority of them, luckily enough, are excellent and harmless. But it must be remembered that, with a few exceptions, all of these so-called breakfast-foods, whatever the labels may say to the contrary, are utterly unfit for children's food unless they are thoroughly cooked. It is best, indeed, to boil them for several hours, and this, of course, may be done most conveniently the day before. In the morning all that is necessary is to warm them over and add hot milk. A child two and a half or three years old should be given a single cupful.

It is essential that the eggs given to small children be of undoubted freshness, for those of the cold-storage variety, besides being unpalatable, are not easily digested. One minute's boiling is all they need. Hard-boiled eggs, as the post-Easter epidemics of stomach-aches prove, are not suitable food for children. Neither is it safe to give a child fried eggs or omelets, since in both of these agreeable dishes the albumen of the egg is converted into a greasy, leathery and indigestible fabric.

Milk should be the drink at breakfast for all children until their tenth year. They should never drink coffee or tea under any circumstances, nor at any hour of the day, and even cocoa is an ill substitute for milk. A single cupful, warmed, is sufficient at breakfast, since it is taken, not to relieve thirst, but as a food. Every child (and every adult, too, for that matter) should take a drink of water upon arising. Breakfast may be begun within twenty minutes thereafter without harm.

Until it is three years old, the child's midday meal should consist chiefly of meat-broths, chopped or scraped meat and potatoes (boiled or baked). Beginning with very small portions, green vegetables, such as spinach, beans, celery, young lettuce well cooked and mashed, may be added, and as a dessert at the end there may be part of a baked apple or pear (the skin and seeds removed), or a few stewed prunes, seeded. Water, but no milk, should be given with this meal.

After its third birthday the child may safely enlarge its animal 
diet by the addition of roasts and chops, poultry and fish, but it is well to serve all of these things finely chopped until the fifth or sixth year, since all children, even when their teeth are equal to the task of masticating meats, are likely to bolt them without proper chewing. The daily allowance should be not more than a few ounces, and it should be reduced on the first indication of digestive disturbance.

Needless to say, all forms of pork are dangerous, and no child should taste the flesh of the swine until its eighth or ninth year, at least. In particular, such things as bacon, ham, shoulder and sausage should be avoided, and the same may be said of all parts of beef, mutton and poultry, save the finest cuts. A child's stomach is ill fitted for the digestion of giblet-stew, liver and bacon, sour beef, calves-head, bologna sausage, pigs' feet and other such delicatessen. Similarly, it can ill cope with fried chops or fried fish. The best meats for it are beef and mutton, boiled, broiled or roasted, and the best fish are the larger ones, which may be boiled or baked. Under poultry I include chicken (broiled or baked, but never fried), roast turkey and roast barn-yard duck.

Many mothers are under the impression that all vegetables, without exception, have excellent dietetic and medicinal virtues, but this is not true, even in the case of adults. With children it is well to avoid all save those which may be boiled for several hours, and to make a further extension of the ban to cabbage sprouts and corn. The vegetables which enter into a meat stew, such as potatoes, carrots, turnips and onions, all well boiled, are nourishing and harmless, and the same is true of spinach. But it must be remembered here that "well boiled" should be taken literally. It is not sufficient to boil carrots until they are tender. Instead, they must be cooked to pieces.

Of all the fruits which may enter into the midday dinner the apple, peeled, baked and seeded, is by far the best. After it come its near relatives, the pear and peach. It is well to bake or stew all three before giving them to children, at least until the age of six or seven years, but the juice of the peach, without the pulp, is harmless. In the same way, the juices of tamarinds, grapefruit and pineapples may be fed to children, even as early as the third year, with safety and benefit, whereas all of these fruits, eaten in the ordinary way, are exceedingly dangerous. It is true enough that many children eat them, but it is also true enough that many 
children die of cholera infantum and diarrhea. They harbor germs, their woody pulp is indigestible, and some have numerous seeds. Cherries and the smaller berries are undesirable also, and bananas, while seedless and germless, overburden the stomach.

The third meal of a child's day, taken in early evening, should be much like its breakfast, save in the absence of the morning egg. Milk and toast or milk and a cereal should constitute its mainstay, with a cupful of milk added. At these two milk-meals no meat, vegetable or fruit should be served. Until its eighth or ninth year a child should never eat meat more than once a day, and no fruits should be served when milk is on the table.

As soon as the three-meal-a-day schedule has been established the child should be refused all solid food between meals, but it is a good custom throughout childhood-and necessary until the seventh year-to give a generous cupful of milk in the middle of the morning and another in the middle of the afternoon. If the child is hungry, let it drink two cupfuls, and, on the other hand, do not press it to drink if it is not so disposed, as the appetites of children vary as much as those of adults.

In conclusion, remember this: that until it is fourteen a child is not capable of dealing with the miscellaneous mass which makes up the civilized bill of fare. If it must eat at the family table, see that its share of the dishes is rigorously limited. Discourage the use of coffee, chocolate and tea, and give it little, if any, pork in any form. Hot rolls, waflles, pancakes and other things of that sort, are always dangerous.

In the matter of candies and other sweets exercise a stern censorship. If it were possible, it would be well for the children of the land to grow up in ignorance of these delights. Nevertheless, every mother may do much to discourage the ancient custom of making candy a reward for diligence and good order. A child however needs some sugar and should have a little on its food.

\section{QUESTIONS FOR THE MOTHER ABOUT CHAPTER VIII}

Why has a child's diet more to do with its future welfare than any other thing?

The correct diet of a baby and child is responsible for the bone, 
teeth, muscle, physical reserve, mental capacity that is needed by a successful adult.

The following bills of fare for young children were prepared by Dr. Charles V. Chapin, Commissioner of Health, Providence, R. I., May, 1909.

\section{FROM 12 TO 15 MONTHS}

Accustom the child to drink from cup and take food from a spoon. Five meals should be given in 24 hours.

\section{Breakfast}

Cup of cow's milk, a saucer of oat meal or barley flour jelly, with milk, or cream of wheat with milk. The oatmeal jelly is made by putting 4 tablespoons of coarse oatmeal into a pint of cold water, let it stand 24 hours and then boil it down to $\frac{1}{2}$ a pint and strain through a coarse cloth. What goes through is oatmeal jelly, and may be kept in a cool place. Make a fresh supply every day. Milk may be warmed to suit taste; it should not be iced.

\section{LUNCH}

Cup of cow's milk.

\section{DinNer}

Broth or beef juice, bread a day old crumbed in milk.

\section{SUPPER}

Bread crumbed in milk.

If possible, give two to four tablespoons of orange juice, or other fruit juice in season before morning lunch. Be sure the fruit is sound and ripe. Do not give fruit juice at same time as milk.

Water may be given as desired, but sparingly at meals.

\section{FROM 15 TO 18 MONTHS}

\section{Breakfast}

Cup of cow's milk, saucer of oatmeal jelly, with milk or flour or Indian meal gruel, with milk, small piece of bread a day old with butter. 


\section{LUNCH}

Cup of milk, small piece of bread and butter.

\section{Dinner}

Broth or beef juice with boiled rice or barley, and a small piece of bread and butter.

\section{Afternoon Lunch}

Cup of milk.

\section{SUPPER}

Cup of milk, bread a day old and butter, a little apple sauce or pulp of stewed prunes or baked apples with skin and seeds removed.

Water may be given as desired, but sparingly at meals.

\section{FROM 18 MONTHS TO 2 YEARS}

\section{Breakfast}

Cereal and milk. Cup of milk. Bread a day old and butter.

\section{LUNCH}

Cup of milk with bread and butter, or simple crackers, or Indian meal Johnny cakes and milk.

\section{DiNNER}

Broth with boiled rice or barley, or eggs, soft boiled or poached, baked or mashed potatoes with butter and salt, bread and butter.

\section{Afternoon Lunch}

Piece of bread and butter.

\section{SUPPER}

Milk, bread and butter, or milk toast, pulp of baked apple, apple sauce, stewed prunes or ripe fruit according to season.

Water may be given as desired, but sparingly at meals.

\section{FROM 2 TO 3 YEARS}

Additions to the diet must be gradually made by selecting articles from the list below, always giving small portions at first, and 
never trying two new articles at one meal. All food must be finely cut or mashed, and well chewed.

Select from the following articles: milk, eggs, soft-boiled, poached or scrambled, baked or mashed potatoes, young peas or beans, scraped beef, white meat of chicken, boiled fish, oatmeal, hominy, wheat-germ, cream of wheat (all these cereals being thoroughly cooked); broths and soups; white and graham bread a day old, toast, zweiback, plain crackers, milk toast, junket, plain custard, corn starch pudding, bread pudding, blanc mange, ice cream, rice pudding; oranges, baked apples, apple sauce, stewed prunes and pulp of peaches and pears if ripe and sound.

\section{FROM 3 TO 6 YEARS}

From 3 to 6 years select in addition from the following articles: beefsteak, roast lamb, stew of mutton or beef, hash of mutton, beef or fish; mutton or lamb chop, corned beef, baked beans, string beans, spinach, asparagus, summer or winter squash, beets, carrots, turnips, tapioca pudding, molasses gingerbread, sugar or molasses cookies, grapes (with seeds and skin removed), bananas (if ripe), melons.

During the 3 to 6 years four meals should be given at regular intervals, as, 7 A. M., 10 A. м., 1.30 P. м. and 5 P. м.

The following is suitable for a child of four years:

\section{Breakfast}

Juice of half an orange, two tablespoonfuls of cereal with milk and sugar or salt, glass of milk, bread and butter.

\section{LUNCH}

Glass of milk or cup of broth, bread and butter or crackers.

\section{DINNER}

Two tablespoonfuls of stewed meat finely cut, tablespoonful of baked potato with butter and salt, a tablespoonful of green peas well mashed, bread and butter, a cup custard.

\section{SUPPER}

Milk, bread and butter, a tablespoonful of stewed prunes. 
Do not give articles on the following list till the child is four years old, many of them not until seven years old.

Fried meats and vegetables, cabbage, raw or fried onions, raw celery, cucumbers, tomatoes, lettuce, radishes, egg plant or green corn, hot bread or hot rolls, buckwheat or other griddle cakes, fruit cakes, pies, tarts, doughnuts, candy, nuts, tea, coffee; never give children wine, beer or cider.

When children are constipated, do not dose them with medicines but consult a physician. If children over two years of age are constipated give them more vegetables, ripe fruit, stewed prunes, oatmeal, molasses gingerbread, rye mush and molasses, rye bread and Graham bread. Avoid wheat bread and crackers. 


\section{CHAPTER IX.-WHAT YOU OUGHT TO KNOW ABOUT YOUR SCHOOL}

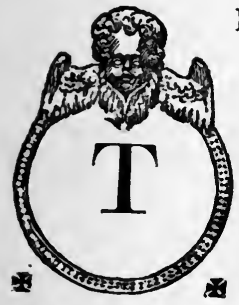

HE German doctors have invented the term "school sickness" to describe a malady which is even more wide-spread, I fear, in the New World, than in Germany. It is the direct product of the ancient pedagogical doctrine, that the more a child is forced to study, the more it will learn. A healthy youngster, this doctrine, is converted into a weak, sickly and inefficient being, with ragged nerves and a bad stomach. Its mind, perhaps, has acquired a mastery of the scale of $\mathrm{G}$ minor and of many irregular verbs, but its blood has forgotten how to grapple with germs.

The schoolmarm, like the loving mother, is too assiduous in her attentions. The mother, coddling her child, measurably increases its chances of death (as I have shown in past chapters); and the teacher, seeking to lead it too precipitately into the Elysian fields of knowledge, sadly over-burdens its brain and its eyes, its lungs and its muscles, its back and its nerves. The result of this classroom forcing is entirely and inevitably pernicious. No good can possibly come of it.

The teacher, I suppose, is really not to blame, after all, for if the mother were not behind her egging her on to her sinister task, she would probably let indolence serve the benevolent purpose of mercy. As it is, she is expected to convert the baby of four or five years into a virtuoso with an extensive repertoire of kindergarten arias; and by the time the poor child is seven, she must have instilled into it a comprehensive grasp of spelling, arithmetic, reading, writing, Mexican bead-work and plain sewing. The mother of such a prodigy is proud of its attainments, and feels a glow when bored friends hypocritically marvel. Later on she will wonder why her child has watery eyes, constant colds or round shoulders.

As a matter of fact, it seems to me to be very unwise to send a 
boy or girl to school until the age of eight, at least. In America, six is the common age for beginning with the three R's, and four and a half the age for kindergarten mummery, but it is entirely improbable that this early start is an advantage, even if the mere accumulation of knowledge be accepted as the sole aim of education. It is beginning to be recognized more that the child which begins school at eight is far more capable of learning quickly than the child which begins at six; and at ten the former is almost certain to know as much as the latter, despite the fact that one has had four years of schooling, while the other has had but half as much. And after that, there will begin to appear a noticeable difference between the two. The one will bear some permanent mark of its too-early bending over desk and slate; the other will be a healthy animal.

The healthy boy of six displays little or no inclination to dally with books. His thirst for knowledge is satisfied by the accumulation of a vast store of baseball lore, with many intricate subtleties of rule, precedent and decision; and his natural yearning to be up and doing finds its proper outlet in purely physical activity. He eats plain, wholesome food, and he spends at least ten hours of the twenty-four in sleep. Between meals he is in the open air, galloping, marauding and fighting his fellows. $\mathrm{He}$ is a savage, true enough-but that touch of savagery will be worth more to him than Greek in the years to come, when he is a grown man doing the hard work of the world, and needs an abounding reserve of brute vigor to draw upon.

Against this tough and uncultivated boy place the typical young pundit of his years. This last is a master, not only of the spelling-book, but also of the works of Oliver Optic. He is studious and his parents are proud of him. Instead of chasing three-baggers in the outfield; he traces the course of the river Amazon. He is quiet, reserved, polite, obedient-and has a touch of mild vanity. He has no liking for the barbarous sports of other boys. He excels at none of their games. At a baseball match he is content to keep score.

Such a boy I believe, is as abnormal as a boy with an obvious physical deformity. Instead of being encouraged in his unhealthy studiousness, as is commonly the case, he should be taken from school and, to borrow a lowly term, "turned out to grass." That is to say, he should be led, willy-nilly, into the savage mode of 
life of the normal boy, in the hope that it will awaken in him some spark of the savage. His dislike for games is really nothing but a feeling of physical incapacity. He realizes that he is not as strong and tough as other boys, and so he shrinks from competing with them. Let him put his books aside for a while-let him straighten up his bent back, breathe pure air, get wet by the rain, and make acquaintance with splinters, bruises and sunburn - and his shrinking will begin to disappear. Some day, let us hope, he will have progressed so far that he will return home with a black eye, acquired honorably in open and valiant combat. When that day arrives, it will be time to send him back to school.

Three hours a day is enough study for any child during its first year or two in school, and this period should be broken by a recess of at least half an hour. In many large American cities the day's session is divided into two parts-one of two and a half or three hours and the other of two hours or less, with an intermission of an hour or an hour and a half. This is rather too much for the child of seven or eight, especially since home study is commonly added, but there is one saving grace to the scheme, and that lies in the long midday recess.

It is very important that the meal eaten during this recess be a warm one, and whenever possible it should be prepared and eaten at home. Until a child is ten or twelve years old it must have its dinner, or principal meal of the day, at noon. The rest of the household may dine in the evening, but for the youngster so heavy a repast near bedtime is certain to be deleterious. A bundle of cold sandwiches will not serve as a substitute for the midday dinnner, for the child needs not only the warm, home-cooked food, but also the walk home, the change of scene, the bit of play on the way, and the hour's forgetfulness of lessons.

Sitting still for two or three hours is an exhausting and painful proceeding to a child of seven or eight. It is as painful, almost, as it would be for a grown man to stand immovable for the same length of time. The child, unable to bear the strain, is apt to lounge in some unhealthful manner. Out of this lounging-this resting upon the desk-come round shoulders. And out of round shoulders come a host of ills.

The strain upon the back, in school, is equaled by the tax upon the eyes. If blackboards were really black, they might justify their existence, but in practise they are usually a dirty gray, 
which reflects the light in blinding flashes and subjects the eyes to harassing duty. From them the child turns to its book-and there it encounters more assaults upon its vision. The fruits of this eye-strain are so many that it would be impossible to catalogue them. They range from irritability and headache to serious derangements of the digestion.

How many mothers who read this have ever entered the schoolrooms in which their children spend from four to six hours a day? It is not common, I believe, for such visits of inspection to be made, and in many places they are no doubt discouraged by the pedagogic authorities, but they are plainly a part of every mother's duty. You may find that your child is forced to sit all day beside a drafty window or near a heater; that it is so far from the blackboard that it can scarcely see; that it occupies a desk too large or too small for it; or that its schoolroom is a dark, evil-smelling, ill-ventilated place.

Suppose one or another of these conditions is found? What can you do to remedy it? Well, you can protest, certainly, and if your single protest does no good you can get other mothers to protest with you. If the school is a private one, and you are paying tuition, your objections will be heard politely enough; and even if it is a public school, and the principal is entrenched behind the patronage of the ward boss, you will not find him so independent as you may think. The disgusting condition of the public schools in many American cities is due almost entirely to the lethargy of parents. Whenever and wherever there has been intelligent and active criticism of school methods and housing, substantial reforms have followed. Even a ward boss has a healthy respect for the collective indignation of a party of mothers.

If, after exerting your best efforts to work improvements, you find that alarming conditions still exist, take your child away from school, by all means--especially if it is still under nine years old. It is during the first few years that the greatest damage is done, and the least advantage gained by risking it. I am firmly convinced, indeed, that the average school does more harm than good to all children under nine. Too many are herded into one class, and too little attention is paid to individual idiosyncrasies. The theory is that all children of an age are alike-a theory comparable, for soundness, to the political doctrine that all men are equally capable of voting intelligently. The bright child is retarded by 
the stupid ones, and the healthy child is contaminated by the unhealthy child. The level that is thus attained is a very low level, indeed.

No doubt there has occurred to many readers a practical objection to one part of my argument. It is this: that if a child be kept from school until it is eight years old it will go through its whole period of schooling two years behind the child which began at six. The children in a school are not taught individually, but in classes, and after it is once entered in a class, a child's rate of progress is the class rate of progress.

In answer to this, let me suggest that the child be kept from school, not only until it is eight, but until it is ten. Let it spend its whole time at play until it is eight, and then let it begin to study at home, either under its mother's supervision or in care of some competent teacher. If it begins with two hours a day, and proceeds to three and finally four, it will be fully as far advanced, after two years, as the child which has spent four years picking up a haphazard knowledge of the rudiments in the average schoolroom. It will then be possible to enter, not in the first class, but in the fifth, and it will go through the succeeding classes with children of its age.

The labor of teaching a child the things taught in the first few grades of a primary school is not nearly so forbidding as you may imagine. In the classroom the individual child gets no more than a few minutes of the teacher's undivided attention a day, and yet it makes progress. If you fancy that it derives much benefit from the instruction given to the other children, you have but to visit a classroom to be undeceived. On the contrary, most of its time, when it is not actually performing its own day's task, is spent in necessary, if unlawful, efforts to relieve the intolerable tedium of its imprisonment.

I am convinced, indeed, that an ordinarily intelligent child, with an hour's individual instruction a day, five days a week, can make far greater progress than the average child in the average classroom. And just consider what it gains! Instead of being shut up for hours in a noisy room, it has one hour of work and all the rest of its time for play-for fresh-air and healthful muscular activity. If it arises moody or dull, its hour of study may be removed from morning to afternoon, or divided into two half hours. It may devote the whole of the rare, bright days of Win- 
ter to play, and make up for its lost time on stormy days. It will have a clean, airy room for study, with no distractions; warm meals; and no home-study tasks for the evenings.

Later on, of course, the school will begin to reckon-if only for the salutary effect that its rough democracy and emulation have upon character. But for the very young child the classroom holds out few advantages. It is the easiest way, perhaps, but it is always the way of headache, anemia, lassitude, nervousness, hysteria and broken health.

\section{QUESTIONS FOR THE MOTHER ABOUT CHAPTER IX}

Why do you send your child to school?

To fit him for life-to make him a self-supporting, self-respecting, happy citizen. What is the first essential to this-good health - with it nine-tenths of the battle of life are won.

What are the years when health is established?

From birth to 16 years of age.

How many of these years are spent in school?

Ten or eleven.

Could an unhealthful school environment unfit a child for life? Yes, it often does.

How?

Bad air breeds contagion. Bad air and contagious diseases undermine a child's vitality-poor light, dirty windows, shiny blackboards, fine print, glossy paper, too much close-range work strain a child's eyes. Eye-strain causes indigestion, nervousness, injured eyesight. Ill-adjusted desks cause round shoulders, curved spines, restlessness. Too little recess,-relaxation from application to lessons-overstrains the child's nerves and disgusts him with school work or any work.

Dust, dry-sweeping, unclean rooms spread tuberculosis-sun, fresh air, soap and disinfectant kill tuberculosis germs.

Cold lunch eaten at school gives a child indigestion-malnutrition. Every child should have a hot, hearty, nourishing dinner, at noon, at home if possible.

Should not the place where your child spends the greater part of his days for at least 9 months in the year, receive every mother's individual attention? 
By all means. Neglect of the school environment might mean life-long failure to the child and disappointment to the mother and father.

What should a mother look for in her child's school?

Open windows, a schoolroom thermometer, adjustable desks adjusted,-clean floors-scrubbed-not dry swept,-good light for every child in the room-recess out-of-doors-individual drinking cups, individual towels.

Cleanly dressed children.

A medical inspector to examine the children for contagious diseases-such as consumption, measles, scarlet fever, pneumonia, diphtheria, mumps, colds, sore throats, tonsilitis, scabies, pediculosis. A physician to examine children for physical defects such as bad teeth, adenoids, enlarged tonsils, defects of hearing and sight, tuberculosis.

Are these things absolutely essential to the good health of school children?

Yes.

What should a mother do if she finds these essentials lacking?

She should go to the principal of the school and ask to have defects of school equipment rectified. If the principal cannot do this she should go to the school board and make complaint. If the school board will or can do nothing, she should put the matter before the citizens of her town, either through the local paper, Mothers' Club or Citizens' Union. No government can long resist the demands of a number of parents for the welfare of their children.

What should a mother do if the school doctor finds physical defects in her child?

She should at once send the child to a physician, dentist, or surgeon and have the defect rectified. If taken in time the child can usually be made normal. If neglected its health will be undermined.

Should children with tuberculosis be allowed to be in school with other children?

\section{Never.}

In some cities there are special schools for tuberculous children. It is not safe to risk infection of well children. It is very unfair to the tuberculous child. It needs fresh air all the time, very little mental effort, plenty of rest and sleep, large quantities of milk and eggs and the constant attention of a physician. 
How can the tuberculous children be weeded out?

Every child should be examined for tuberculosis before entering school each fall. Children with tuberculous parents should have special tests. Their sputum should be examined bacteriologically and a tuberculin skin test made. Children who have not tuberculosis, but have tuberculous parents, or are especially weak, should be in school but part of the day; the rest of the day they should be out-of-doors or resting. They should have a feeding of milk and eggs between meals, morning and afternoon. 


\section{CHAPTER X.-NEED EVERY CHILD HAVE "CATCHING DISEASES?"}

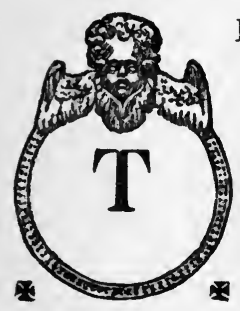

HE notion that every child is doomed to suffer from catching diseases at some time during its first ten years, is a dangerous and stupid error. There is no more reason why a child need have diphtheria, scarlet fever, measles, or whooping cough than why it need have smallpox, lockjaw or hydrophobia if proper preventive methods be used. All these infections are preventable.

What is the best method for the prevention of contagious diseases? Thorough physical examination of the child at frequent intervals; a healthy condition of mouth and teeth; removal of enlarged tonsils or adenoid growths; care and isolation of a child with a cold or sore throat; living and sleeping in the fresh air.

Why do bad teeth, failure to brush teeth daily, neglected tonsils and adenoids favor contagious diseases?

Because germs lodge in decayed teeth and in the unhealthy tissue of tonsils and adenoids.

Why does neglect of colds increase contagious diseases?

Because a cold is often the first sign of such diseases as whooping cough, measles, scarlet fever, etc., at the time when these diseases are most infectious. Because a neglected cold may often result in pneumonia or tuberculosis.

What are the first steps to take when a child comes down with a contagious disease?

Send for a doctor. Put the child to bed in a well-aired, sunny room. Keep it away from other members of the family. Keep persons who have been exposed to the disease away from other people or school. Report the disease to the board of Health; put a notice on the door stating that the disease is present in the house.

What is the invariable treatment for contagious diseases?

1. Fresh air. 
2. Complete quarantine.

3. Disinfection of all sheets, dishes, clothing used for the patient.

4. Fumigation of the room.

5. Thorough examination of the child by a physician on recovery to prevent further complications.

6. Nourishing food, such as fresh eggs and milk, outdoor life and rest.

What should your medicine chest contain?

Absorbent cotton, aseptíc gauze, carbolic vaseline, castor oil, hot water bag, and No PATENT MEDICINES. 


\section{CHAPTER XI.-IF YOUR BABY HAD DIPHTHERIA}

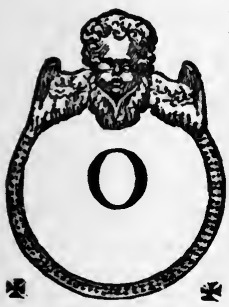

$\mathrm{F}$ all the maladies that afflict small children none causes more terror to the agonized mother than diphtheria. It has an air of mystery and awfulness. It seems, almost, to presage certain death. The doctor's reluctant verdicthis brief, but positive orders regarding isolation and nursing-the mention of antitoxin, of antiseptics, of subcutaneous injections-the posting of the warning sign upon the door-all of these things bring the mother of the little patient to a pitiable state of alarm.

And yet, for all its indubitable dangers, diphtheria is one of the diseases that modern medicine may fairly claim to have conquered. Its cause is known and its course is known. It may be prevented, and in the great majority of cases it may be cured. When the doctor pronounces its dread name, there is no reason whatever why one should give thought to grievous possibilities, because these possibilities, fortunately for the human race, are now happily remote. Ten years ago more than half of the babies who took diphtheria died from it. To-day the deathrate is less than onetenth, and, under conditions easily attainable, than less onetwentieth.

The credit for this belongs absolutely to the men who devised and perfected diphtheria antitoxin. No other single medical discovery of recent years has better proved its value to the human race, or better justified the bold experimentation-the ruthless slaughter of rabbits and guinea pigs-the patient toil with culture tube and microscope- of medical science.

No doubt you have heard assertive persons say that antitoxin is a snare, and that it kills more babies than it cures, and perhaps this sort of criticism has made some impression upon you. If it has, be warned in time. Your own child may take diphtheria tomorrow. If it does, antitoxin is the only thing under the sun that will aid it. When your doctor tells you so, show your faith in him 
by letting him go ahead with his work of inoculation. Half an hour's delay means regret poignant and everlasting.

To understand the nature of diphtheria antitoxin it is necessary first of all, to know something about diphtheria. In the view of the layman it appears as an extraordinarily violent species of sore throat, with an unaccountable tendency to infect others and to end in death. In the view of the pathologist it is an acute infectious disease of the first class, caused by a definite organism called the bacillus diphtheria, which secretes a powerful soluble toxin, or poison; which, in turn, produces death by inhibiting the proper action of the heart.

The bacillus diphtheria, despite the popular notion of bacilli, is not an animal, but a plant. Unlike the varieties of vegetation that are most familiar to us, it does not need an immovable soil for its roots, but floats about and grows luxuriantly in the human blood, or in any other suitable liquid. It is so small that a microscope magnifying one thousand times barely reveals it. In shape it resembles a minute rod, rather thick in section, and with one end swelling out a bit. It tends to grow in curious little clusters which much resemble the five outstretched fingers of a human hand.

The bacillus diphtheria is very tenacious of life, and even when dried and seemingly withered, it is capable of remaining alive for months. This explains the fact that it is very difficult to stamp out an epidemic of diphtheria. Once the bacilli gain a foothold in a house, a school or a neighborhood, they are very apt to infect child after child. They float about in the air; they appear, in countless millions, in the mouths of children who are ill with the disease; and they appear, too, though in less number, in the mouths of those who may be perfectly well. Only the most skilful use of antiseptics, by some one with sound scientific knowledge, is of any value in the effort to stamp them out.

When a swarm of these bacilli take lodgment in a child's throat or tonsils, they begin at once to increase and multiply. Within a few hours they are present by the billion. Each individual throws off a minute stream of poison, and these streams, commingling, attack the throat tissue. They kill the mucous membrane, and the little blood-vessels below it rush scar-forming materials to the scene to repair the damage. At the same time the white blood corpuscles in the blood vessels engage the bacilli in combat- 
attacking them and trying to swallow them. Before long the scene of the battle is littered with all sorts of débris-dead membrane, dead bacilli, dead corpuscles, and bits of scar tissue. This débris, in the end, forms quite a large mass, and becomes, in fact, the familiar diphtheria throat membrane.

The membrane obstructs the windpipe of the sufferer, and unless something is done to break it strangulation is apt to follow. Sometimes it is necessary to cut into the neck of the patient below the place of obstruction and insert a silver tube, to give the lungs air. More often, it is possible to force a tube down the throat, in front of the membrane. This operation requires great skill, and should be entrusted only to some expert who has done it often before.

Despite the size and toughness of the membrane, however, strangulation is seldom the cause of death in diphtheria. Much more often, the patient dies of heart failure, produced by the activity of the poisons secreted by the bacilli. These poisons are frightfully virulent, and being soluble they are carried to all parts of the body in the blood stream. It is evident, therefore, that if they can be attacked and destroyed in the blood their power of doing damage may be broken. This office of attacking and destroying them is the function of diphtheria antitoxin.

The manufacture of the antitoxin is based upon the fact that healthy blood, whenever germ poisons appear in it, begins automatically and at once to make antidotes for them. Inject a few drops of diphtheria poison into the veins of a healthy, full-grown man, and his blood will at once neutralize it, and as a result he will show no bad effects whatever. If the amount injected be very small, his blood, indeed, will manufacture a great deal more antidote than is necessary to neutralize it, and will keep on making antidote for some time after all of the poison present has been rendered harmless.

But if a large quantity of poison be injected, or if active bacilli in large numbers are lodged somewhere in the body, and are hard at work sending forth more poison, the blood will soon give up the hopeless struggle. It will fight valiantly as long as possible, and in the course of the battle it will neutralize a vast quantity of poison, but in the end the enemy will be too strong for it, and it will surrender. This is what happens when a child is infected with diphtheria and a colony of bacilli lodge in its throat. For a while its 
blood fights on, but in the end it is overcome, and the poison begins to course, without obstruction, through its veins.

Fortunately, it is possible to lend the body aid by reinforcing it. And how? Simply by injecting into the patient's veins blood from some animal which is capable of making a better fight against diphtheria than a human being. In practise the animal selected is always the horse. It is a hardy, cleanly and healthy beast; it is capable of losing a great deal of blood without damage; and its blood has a peculiar capacity for opposing and neutralizing the poisons of the diphtheria bacillus.

A fine, strong horse is selected, and the manufacture of antitoxin is begun by injecting into one of its veins a small amount of diphtheria poison. The amount is so small that the blood of the horse neutralizes it at once, and the animal suffers no ill effects at all. Four days later twice as much poison is injected. This, too, is neutralized by the horse's blood, and in addition, the blood, stimulated to activity, manufactures a large extra portion of antidote. Four days later a still larger dose of poison is administered, and thereafter for six months the process is kept up. The horse's blood, in the long battle, always manages to keep a bit ahead of the poison. At the end of the six months, it is so heavy with antidote that it is capable of neutralizing any conceivable amount of poison. The horse, in fact, is utterly diphtheria-proof. One might inject into its veins enough diphtheria poison to kill an army, and it would go unscathed.

All that remains is to draw off some of this immunized blood and get it into the veins of the human patient. The process, it is obvious, is a very simple one. One of the veins of the animal is opened, a quantity of its blood is collected, and a portion of this blood (after it has settled and has been strained) is injected into the human patient. The strained blood is a sticky, yellowish liquid. It is what the doctors and druggists call diphtheria antitoxin.

This antitoxin, then, is nothing more than horse blood which has acquired an extraordinary capacity for combating diphtheria poisons. When it enters the blood-vessels of the patient it begins at once to seek out the diphtheria poisons and destroy them. It does its work almost instantaneously, and if enough is used, the result is certain. All of the diphtheria poisons are neutralizedand the patient begins to grow better.

But it is plain that the antitoxin must be used quickly and in 
sufficient quantity if this desirable end is to be achieved. So long as the patient's blood fights on unaided, the amount of poisons present in it will go on increasing. By and by these poisons may be present in such great quantity that they will begin to impede the action of the heart. When that stage is reached the patient is dying, and it is too late to battle with the disease.

Therefore, it is important that the diphtheria antitoxin be used just as soon as there is good ground for believing that diphtheria is present. If it is used on the first day of the disease, the latest statistics show that it will save the lives of ninety-eight patients out of one hundred. If its use is put off until the second day, it will save only ninety-six. If it is used after the fourth day, it will not save more than eighty out of a hundred.

And it must be used in sufficient quantity. If one injection does not bring relief, let there be another, and then another, and yet another. The antitoxin can do no harm. In cases on record, wherein its use has long been delayed, almost incredible quantities have been injected. The scientific physician has a safe rule. He knows that there is hope so long as life lasts; and so he proceeds with the treatment until the danger line is passed and the patient shows signs of it.

You mothers learn a great deal about the care of children, but in the presence of a disease as dangerous as diphtheria you must yield up the custody of your child to the doctor and the nurse. Your family doctor must be a man in whom you have implicit confidence. Select him with the utmost care, and do it, by preference, at some time when there is no sickness in the household. Then, after you have chosen him and sickness comes, give him the faith and support that his learning and experience deserve. His whole life is devoted to the cure of human ills, and your common sense will teach you that, if he is an intelligent man, this devotion must profit him in wide knowledge.

Do not oppose him or hamper him in the sick-room. He knows what is best for the patient. If he proposes to use antitoxin, let him do so at once. The persons who go about denouncing such invaluable gifts to the human race are the heirs of those ancient wiseacres who laughed at Sir William Harvey when he said that the blood flowed through the veins, and hooted at Jenner when he proposed to vaccinate all England, and called Klemke a lunatic when he maintained that tuberculosis was infectious. 
That antitoxin, employed in time, will cure diphtheria is a fact as easily demonstrable as the fact that the sun rises every morning. And the fact that nothing else in the world-no medicine, throat mopping or surgical operation-will cure it, is demonstrable, too. Medicines and moppings have their usefulness as aids, but it is the antitoxin-or, when the antitoxin is not used, long-suffering nature-that wins the battle.

It is evident, however, that the antitoxin, while it neutralizes the poisons secreted by the bacilli, does not directly kill the bacilli themselves. The business of getting rid of them falls upon the white blood corpuscles, and the great majority of them are soon gobbled up, but not a few remain. These, unless something is done to kill them, are apt to infect other persons. Active germs have been found in the throats of recovered diphtheria patients three months after the disease itself apparently disappeared, and there is one remarkable case on record, where they remained alive for twenty-two months. They also live in the air, in water, and elsewhere.

In consequence, it is highly important that children who are convalescent be kept away from other children. They should be isolated for at least a month, and it is unwise to send them to school for several weeks longer. The business of stamping out the stray bacilli which may happen to infect the sick-room should be entrusted to some one who knows how to do it. The common device of hanging up cloths saturated with carbolic acid is utterly useless. In many cities the municipal health department takes charge of all disinfections.

When this is the case, it is very unwise for mothers to offer opposition. The health department experts know what they are about, and their work may very easily prevent other cases in the same house or epidemics in the neighborhood. One little life saved is worth all the bother and disorder that these men, with their enmity to wall-papers, cause in a household.

During the progress of a case of diphtheria, the rooms occupied by the patient-and it is best to have two bedrooms, that there may be frequent changes-should be isolated absolutely from the rest of the house, and it is advisable, whenever possible, to send all the other children of the house away and withdraw them from school until all possibility that they, too, are infected has been eliminated. 
It is best, whenever possible, to call in a graduate nurse, but too often the fear-stricken mother must herself assume the office of bedside attendant. To those confronted by this difficult duty, I would suggest the importance of submitting to a preventive injection of antitoxin. Small doses for this purpose are especially prepared by the various manufacturers. The inoculation causes little discomfort and no illness, but it is a certain preventive. Most adults are immune to diphtheria, but the importance of keeping the nurse in good health throughout the period of nursing is obvious, and so it is well to take no chances.

You should have the doctor give you a prescription for a mouth gargle and use it every hour. In addition you should wash your hands at frequent intervals with antiseptic soap. All spoons glasses and other vessels should be cleansed with a three per cent. solution of carbolic acid. Toys, cushions, carpets, pictures and furniture-in fact, everything movable-should be taken from the sick-room. Its furnishings should be limited entirely to the bed, a table and a chair for the nurse. The floor and walls should be sponged once a day with a one-tenth of one per cent. solution of bichloride of mercury. The bedclothes and garments of both patient and nurse should be boiled, and all sick-room débris should be burned. The eyes, nose and mouth of the patient should be frequently swabbed with moist absorbent cotton, and the cotton should then be burned.

Not a solitary person besides the nurse and the doctor should be permitted to enter the sick-room under any circumstances. As I have said, most adults are immune to diphtheria, but it is perfectly possible for them to carry away the germs and infect children. I recently encountered in my own practice the case of a drawing teacher who infected at least a score of children without being ill herself. The germs of the disease were in her throat.

The nursing of a case of diphtheria requires eternal watchfulness and care. Even when the disease is making favorable progress, there is danger of sudden heart failure and collapse, and the management of such emergencies is beyond the skill of the mother. If your little patient seems to be fainting, and the pulse grows weak, send for the nearest doctor at once. In any case the convalescent is always very much exhausted, and should be kept in bed a good while. The diet should be rigidly prescribed by the physician. It is exceedingly dangerous to add a coveted dish to 
it-no matter how harmless that dish may seem-without his express permission.

Methods of preventing diphtheria will present themselves to the intelligent mother. The notion that every child is doomed to suffer from the disease at some time during its first decade (and to suffer attacks of a long string of other infantile epidemics, likewise) is a dangerous and stupid error. There is no reason whatever why any child need have diphtheria, scarlet fever or measles, just as there is no reason why it need have smallpox, lockjaw or hydrophobia. All of these infections are preventable.

In a great many cases kissing spreads diphtheria-particularly from adults, in whose mouths the germs may be impotent, to children. Therefore, the custom of permitting small children to be fondled and kissed by every sentimental woman relative and visitor, should be under the ban. Again, it is well to break children of the habit of putting things into their mouths. It is easy to do this, and the precaution may save lives. Rubber pacifiers, the toys used to divert children in photograph galleries, and other things of that sort frequently swarm with the bacilli.

As I have tried to show, success in battling with diphtheria depends almost entirely upon promptness. A delay in sending for the doctor is often fatal. Whenever a child's throat is sore, and a membrane obstructs the air passages, it is safe to conclude that there is some diphtheretic infection. Even a mild redness, without membrane, or pain, may indicate the presence of the disease. Such a mild case may pursue an uneventful and unalarming courseand then suddenly end in heart failure. It is best, at all times, to put no trust in home remedies for the treatment of sore throats. Only a physician is capable of differentiating between diphtheria and less dangerous infections.

The so-called "pseudo-diphtheria" of the old-school family doctors is not diphtheria at all, but a milder tonsil infection due to the presence of organisms called the streptococcus and staphylococcus. But the existence of such an infection shows that the little patient's throat membranes afford good soil for germs, and so it should be guarded against diphtheria with unusual vigilance. Bad teeth, mouth sores, enlarged tonsils, catarrhal inflammations and other abnormalities in the respiratory tract also predispose to the disease. Susceptibility is increased, again, by measles and scarlet fever. In the majority of cases, the germs first find a lodg- 
ment in the tonsils. Therefore, it is a wise precaution to have enlarged and sensitive tonsils removed in early infancy.

When a child has been exposed to infection, and the fact is known, an immunizing injection of antitoxin should be made at once. If this is done in time, the disease is effectually headed off. As I have said, the antitoxin is harmless, and cannot possibly injure a healthy child. The prejudice against it (and traces of this prejudice are to be encountered among ignorant, old-fashioned doctors as well as among silly mothers) is doubtless due to the fact that it has been in use but a short while. Not until 1894 was its value demonstrated, and only since 1895 has it been in general use. In these few years, I should say, it has saved the lives of at least three hundred thousand children.

\section{QUESTIONS FOR THE MOTHER ABOUT CHAPTER XI}

What is the one thing that has reduced the death-rate from diphtheria so marvelously in the last ten years?

Diphtheria antitoxin.

How soon should the antitoxin be administered?

As soon as diphtheria is suspected to be present.

How can this be proved?

A "culture" should be taken of the patient's throat.

How is this culture taken?

The doctor scrapes the patient's throat and has the mucous examined at once by a bacteriologist to see if the diphtheria germ is present.

How can a mother protect the family from taking diphtheria from the patient before she is sure it is diphtheria?

She should call a doctor for tonsilitis or a bad sore throat and should isolate a child suffering from a cold or sore throat.

How can she prevent the disease from attacking those who have been exposed to it?

She should at once notify the Board of Health. Either a Board of Health doctor or her private physician will make a mild injection of antitoxin for each person exposed. If the mother takes care of the child she should have such an injection also, as her health is all-important at this crisis.

What can we do to prevent diphtheria? 
Brush the teeth thoroughly after each meal; use a mouth wash; have adenoid growths or enlarged tonsils removed; take care not to infect other people if we have a cold or sore throat. Take care not to let other people infect us if they have a cold or sore throat. Never kiss one another on the mouth.

How can we prevent diphtheria epidemics at school?

Diphtheria germs are present in the mouths of many healthy persons. These persons are called "germ carriers." A "culture" should be taken of every child's throat before it enters school in the fall. In this way the "germ carriers" can be weeded out. 


\section{CHAPTER XII.-IF YOUR BABY HAD SCARLET FEVER}

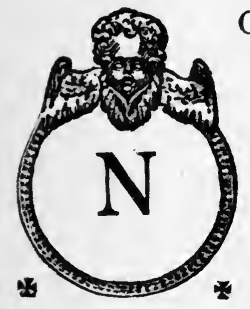

OW that smallpox, thanks to compulsory vaccination, has become a rarity in civilized communities, scarlet fever steps forward as the worst of the eruptive diseases of childhood.

It is a malady of enormous antiquity. Thucydides, writing nearly five hundred years before the beginning of our era, called it a heritage from the remote past. It has scourged the white races in all ages and all countries, and the physicians of all schools have leveled their heaviest artillery upon it. Yet it remains a puzzle unsolved and an enemy unconquered even to-day. We are in doubt as to its cause, and there is as yet no drug or antitoxin that will cure it.

But despite all this, the death-rate from scarlet fever is steadily declining, and we may expect it to decline more and more as the years go by. The reason for this, I take it, lies in the fact that the modern doctor is a great deal more sparing with pills and powders than his predecessor, and a great deal more lavish with water, air and antiseptics. In the old days it was customary to dose scarlet fever patients with all sorts of violent remedies, in staggering quantities, and, as a result, many of them died. To-day medicines are but minor auxiliaries in the sick-room, and both doctor and nurse devote their main energies to preventing a spread of the infection.

Though the exact cause of scarlet fever is still far from certain, there is no doubt whatever that it will be determined with absolute accuracy within a few years. A large number of competent observers, in truth, have already come to the conclusion that the causative agent must be a minute parasite closely related to that which produces malaria. The organisms of diphtheria, tuberculosis and most other common maladies belong to the vegetable kingdom, like the germs of the yeast, but this so-called scarlet fever organism is a true animal. It is at the very bottom of the scale 
of brute creation, and is almost as far below the caterpillar as the latter is below the highest grade of man-like ape.

An attack of scarlet fever may begin a day or so after the patient has been exposed to contagion, and then again there may be an incubation period of a week or even more. Several years ago, in the course of my practice, I one day visited a family in which there were four bad cases. Next day I left the city and remained away for a full week. On the day of my return I fell ill with the disease, and a very severe attack was immediately in progress. In this case the incubation period seems to have been no less than eight days.

Scarlet fever usually begins with chills, rising fever, headache, loss of appetite and pains in the limbs, and sometimes, particularly in very young children, with convulsions. A sore throat and painful tonsils next afflict the patient, and at the end of a day or so the characteristic red rash appears. This commonly begins around the neck and over the chest, and at the start consists of tiny scarlet blotches the size of pinheads. The blotches soon run together and the whole surface of the body becomes a brilliant red. The membranes of the mouth are affected in much the same way, and the tongue becomes swollen and takes on the so-called "raspberry" appearance.

Despite the almost universal notion, there is no crisis in scarlet fever. A crisis, in medicine, means a sudden change in or termination of symptoms. In scarlet fever the fever does not cease suddenly, but slowly. This is called a termination by lysis, which is the very reverse of crisis. When the fever goes down-usually about the fifth day-the scarlet rash begins to disappear and the skin of the patient begins to peel off. Sometimes it comes off in large patches, and the skin of nearly a whole hand may separate in a single piece.

When this peeling has fairly begun, the malady itself may be said to have practically run its course, but there yet remains a grave danger from serious complications. The worst of these are Bright's disease, several varieties of heart disease and inflammation of the inner ear. Bright's disease, as every one knows, may readily lead to long invalidism and death, and inflammation of the inner ear only too often produces meningitis, abscesses on the brain, or permanent deafness. The belief that scarlet fever tends to leave some nasty souvenir of its visit is far from a mere 
superstition. It has an unpleasant habit, too, of paving the way for other acute diseases, such as pneumonia, bronchitis and even diphtheria.

All this makes it apparent that a case of scarlet fever needs very careful nursing. Whenever it is possible a trained nurse should be engaged, and in any event the doctor's orders should be obeyed with scrupulous exactness. Nothing could be more foolish than the common custom of seeking advice in such emergencies from grandmothers, neighbors who have "pulled their own children through" and other well-meaning, but blundering "experts" of that species. Good nursing means not only intelligent care of the patient, and a capacity for quickly and accurately recognizing threatening complications, but also intelligent efforts to prevent a spread of the infection. Scarlet fever is one of the most contagious of known maladies, and in achieving an effective quarantine of his patient the cautious physician often takes measures which, to the layman, may seem almost ridiculously elaborate.

When one of your children develops the disease, put it to bed in a large and airy room, preferably on the top floor of the house, and prepare another room nearby, into which the child may be taken when the sick-room proper is being aired and cleaned. Take all unnecessary furnishings out of both rooms. Under this heading come carpets, rugs, pictures, draperies and ornaments. In the sick-room a bed for the patient and a chair and table for the nurse are about all that may be called needful. A plain clothes-rack will suffice for holding the necessary changes of bed-clothes.

If it is at all possible, send the other children of the household to some relative's home and keep them away from school for a week. If they are apparently well at the end of that time, it will be safe to let them go back to school. If sending them away is out of the question and they must remain in the house, keep them away from all other children until the patient up-stairs is well. They may take the disease at any time, even in the face of careful precautions, and you certainly would be greatly grieved to see them carry it to their fellow-pupils and playmates.

If you are able to engage a trained nurse-or, better still, two of them-the problem of nursing is much simplified, for the nurses will carry out the doctor's orders intelligently and faithfully, and in their comings and goings they will see to it that they do not carry the infection. Your own visits to the sick-room should be as far 
apart as your anxiety will permit you to make them, you should stay but a short while, and avoid handling the patient. Before you enter the room put on a long duster or rain coat that completely covers your ordinary clothes. Place a close-fitting hood, such as housemaids wear when dusting, over your hair. These garments should be kept at the sick-room door. When you leave, wash your hands thoroughly, putting a few drops of carbolic acid into the water. After that, spend half an hour in the open air and sunlight.

If you decide to nurse your child yourself, you must resign yourself to an entire separation from the other children in the house for a period of at least six weeks. Your bedroom should be next to or very near that of the patient, of course, but I cannot advise your sleeping in the sick-chamber itself. Besides increasing the chances of infection, this practice results in unduly vitiating the air of the room. The oxygen that you consume is needed by the child, for in a sick-room the supply of oxygen is never too ample.

With proper treatment, the patient should be quiet enough to give you a reasonable amount of rest, but you must school yourself to awaken easily in order that you may look after its nocturnal wants. It is highly important that you go out every day for an hour or so for fresh air and exercise, and during this time some one else must be on guard. This assistant nurse, during her stay in the sick-room, should wear the long coat and the dust-cap I have already described. You, yourself, on leaving the sickroom, should make a complete change of clothes, and wash your face and hands thoroughly. The clothes you wear outside should be kept in an ante-room.

These precautions may seem unduly elaborate, but in view of the extraordinary infectiousness of scarlet fever, they are not. In my own practice I wear a skull-cap and long rain coat whenever I enter the room of a patient ill with the disease. In addition, I cover my mustache and beard with strips of sterile cotton, and see to the surgical cleanliness of my hands-and this is far greater than ordinary soap-and-water cleanliness-when I depart.

In the sick-room, for general antiseptic purposes, you should keep a wooden (not a metal) bucket filled with a one-tenth per cent. solution of corrosive sublimate. The drug stores sell this powerful germicide in convenient tablet form. Use one tablet for every pint of water. All towels, sheets and other cloths used 
in the sick-room should be soaked in this solution for an hour before they are placed in the family laundry basket. It should be used, too, instead of plain water, for moistening all cloths employed in wiping the floor and furniture.

You know, of course, that corrosive sublimate is a most violent poison, but this fact need not worry you, for a weak solution, such as I have recommended, can do little damage. After it wets your hands, wash them with soap and water. It may make the skin a bit dark and rough, but this will wear off very quickly. In mopping the floor, see that the cloth is moist, and not soaking wet. The sick-room must never be dusty (this bans all sweeping), but neither should it be steamy and damp.

The doctor will give you detailed instructions as to the care of the patient. The little sufferer will probably be greatly annoyed by the discharges from its nose, throat and ears, and these must constantly be looked to. Instead of a handkerchief or napkin for keeping it clean, use small bits of the absorbent cotton sold by every druggist. This cotton is cheap, it has been sterilized, and its application is not irritating. Every piece should be burned immediately after it has been used.

It will be a great aid to the doctor if you can give him an accurate report upon the varying temperature of the patient. To the layman, taking a temperature may appear difficult, but it is really a very simple matter. A clinical thermometer costs less than a dollar, and the doctor will show you how to read it. If the patient is afraid to hold it under the tongue, place it in the rectum. The normal temperature of a human being is 98.6 degrees Fahrenheit. In scarlet fever it may rise to 103 or even 105 degrees. Whenever it begins to grow high, the doctor should be informed at once.

After the fever goes down and the child's skin begins to shed, it will suffer greatly from itching. This can be relieved by rubbing the body very gently with carbolated vaseline. During this stage the child should be bathed often in cold lime-water or in water which contains a small amount of ordinary baking-soda. Hot baths are to be avoided, but the water may be warmed enough, as the phrase goes, "to take the chill off." Do not attempt to help nature by pulling off the pieces of loose skin. They will drop off themselves just as soon as the new skin beneath them is hard enough to be exposed.

The ancient belief that a sick-room may be disinfected by hanging 
up cloths saturated with weak carbolic acid or some other antiseptic is without a basis in fact. An antiseptic, to kill a germ,must be brought into actual contact with it.

That is why all towels and sheets must be not merely dampened by, but actually soaked in, the corrosive sublimate. If you managed to get enough carbolic acid into the air to kill the germs, you would kill the human occupants, too.

Scarlet fever is most contagious from the third to the seventh day, but its contagiousness does not disappear entirely for a long while after that. Until the shedding of the skin and the discharge from the ears have quite ceased, no person save the doctor and the nurses should be permitted to approach the patient, and in any case the period of quarantine should be at least six weeks.

If you have had scarlet fever in childhood you need not fear for your own health, but, even if you haven't, your chances of taking it are small. It is, in fact, rare among adults, but all the same it is well to adopt precautions.

After the patient has recovered, the sick-room should be thoroughly cleansed; and this means cleansed in the surgical, and not in the common, sense. In large cities the work is best entrusted to the health department. When such experts are not available, the floor, walls and ceilings should be mopped again and again with the corrosive sublimate solution, and the windows should be thrown wide open. It is always best to have the wall-paper scraped off.

There is no reason to fear the worst when the doctor's verdict is scarlet fever. In all maladies, you should remember that the death-rate is kept up by the enormous number of deaths among the children of the very poor.

\section{QUESTIONS FOR THE MOTHER ABOUT CHAPTER XII}

What is the one thought you should have in your mind where there is scarlet fever?

The danger of one case of scarlet fever in a town to the rest of the community.

Why?

Because scarlet fever is one of the most contagious of diseases.

Because it is very dangerous and leads to other serious diseases. 
What is necessary to protect a community against scarlet fever?

That every case, as soon as it is discovered, should be reported to the health department.

What will the health department do?

It will send a doctor to examine the child. It will give the mother information about preventing the spread of the disease to the other children in her family or in the town. It will place a sign "scarlet fever" on the door to warn people. It will fumigate the home.

What should a mother do if the health department does not take such care of a scarlet fever case?

She should send at once for her doctor and ask him how to care for the child and how to disinfect. She should place a large red letter sign SCARLET FEVER on her door to protect her neighbors. She should keep all the persons who have been exposed to scarlet fever away from other persons, and the children away from school or play on the street until the time in which they might come down with the disease is passed.

What are the precautions to be taken to prevent infection from scarlet fever?

All sheets, nightgowns, towels, etc., used by the patient and the nurse should be soaked twenty-four hours in a solution of carbolic acid before taken from the sick-room, then thoroughly boiled.

Every dish used in the sick-room should be washed in carbolic acid solution before taken from the room.

Every book, toy or article that cannot be boiled should be burned. A child has caught scarlet fever from a book that had been in the room when her brother had scarlet fever two years before.

No letter written by the patient should be permitted to leave the room. Allowing an infected letter to go through the mails, carrying a child with a contagious disease through the street car or trains is a crime to one's fellowmen that should be punishable by law. If it is necessary to take a child in a hack to the hospital or home, the hack should be fumigated and disinfected before being entered by another person.

How long is there danger of infection from a scarlet fever case?

Until every bit of the old skin-skin that peels off-comes off the body naturally.

What should be done when the patient recovers?

It should be bathed and its hair washed in disinfectant before 
leaving the room. Place a clean wrapper at the door and have clean clothes for it in another room where it may get dressed. Then burn a formaldehyde candle in the room, wash the floors and the woodwork and the walls with a solution of corrosive sublimate. Then the wall paper should be torn off the wall and the room should be repapered.

How much cheaper is this than another case of scarlet fever, perhaps resulting in death. 


\title{
CHAPTER XIII.-WHOOPING COUGH: IT KILLS MORE CHILDREN THAN SCARLET FEVER
}

\author{
AND DIPHTHERIA TOGETHER
}

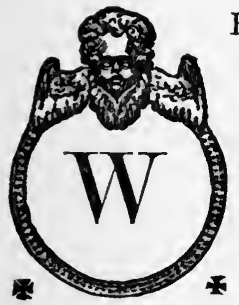

HOOPING cough is one of the most contagious of all maladies of childhood, and, in very young children, one of the most dangerous. Personal contact is not necessary in order to transfer the infection from one child to another. Children may take it by merely entering a house in which there is a patient, and some observers assert that it may even be transmitted from child to child on the street. After the third year it is not often fatal, but among very small children it plays havoc. During the whole of the first year indeed, it shows a death rate of at least 25 per cent. This proves how important it is to guard babies against contagion. The notion that whooping cough is a mild disease, which every child would better acquire early, for its subsequent good, is a costly fallacy.

We are yet somewhat in the dark as to the cause of whooping cough, but there is very good reason to hold that it is produced by a small organism allied to the germs of the other infectious diseases. This organism, it is possible, enters through the mouth or nose and takes up its home in the larynx, where it at once proceeds to irritate and destroy the mucous membrane, and to send forth poisons into all parts of the body. The first result is an accumulation of cellular débris and mucous in the larynx, and the second is a serious interference with the normal working of the bodily machinery, particularly that part of it which makes up the nervous system.

The accumulation in the larynx, it seems likely, is the direct cause of the suffocating cough, though certain observers believe that the principal seat of trouble is elsewhere. Whatever the precise mechanism, it is plain that the effort in the cough is directed toward ridding the larynx of its obstruction, and that the ex- 
pulsion of this obstruction, which comes up in the form of a sticky mass, is followed by a cessation of the paroxysm.

Whooping cough starts like a common cold, and sometimes it runs so mild a course that it is scarcely recognizable. But ordinarily, its peculiar characteristics begin to appear after a few days. One of these is the tendency of the cough to grow worse at night, and another is its tendency to become convulsive and racking. The child gasps for breath after each attack and seems to be much exhausted.

In a week or ten days the familiar whoop sets all doubts at rest. Anyone who has ever heard this whoop will never forget it. It is caused by the labored in-breathing of air through the narrowed glottis, and well exhibits the distress of the patient. The cough itself is violent in the extreme. The child, as if suffocating, grasps at nearby objects, its face grows red, the veins of its neck swell, the tongue protrudes and the muscles of the whole upper part of the body are strained. After each effort to clear the air passages there comes the whoop. Finally, there is a spasm of extra violence, the mass of mucous is expelled, and the child sinks back exhausted.

It is common for vomiting to follow, and in some cases this vomiting is so severe that it becomes one of the most distressing symptoms. At times, indeed, the patient seems unable to retain any food in the stomach. In such cases, of course, the exhaustion becomes progressively more severe, and the physician finds the nutrition of the patient a serious problem.

The number of coughing spells in the twenty-four hours varies greatly, and is modified somewhat by the care exercised in nursing. A sudden draught will often bring on a severe paroxysm, as will a drink of cold water. Children are also apt to start coughing on hearing some one else cough, and any other noise or shock may have the same effect. The paroxysms are always more frequent at night, and between the severe ones there may be a large number of lesser ones.

Very little can be done to shorten or mitigate the paroxysm, once it starts. If the child is old enough to stand alone, it is best, perhaps, not to touch it. If it is in arms, it should be held gently, but firmly. Inhalations are often of value, but they can be used to better advantage between the paroxysms rather than during their progress. Often the mucous coughed up is bloody, and there may 
be bleeding from the nose or throat. Unless this is very profuse it need cause no alarm.

The whooping stage continues for from three weeks to two months, after which the cough grows milder, the vomiting ceases and the child begins to regain strength. Even when there are no complications, whooping cough is a very exhausting malady, and so it is necessary to observe the child closely during convalesence. It should get plenty of fresh air, but it must be guarded against cold, for an ordinary cold, at this stage, may quickly lead to pneumonia. A visit to the seashore, if it does not involve a long journey, and the weather is fine, is an excellent means of hastening convalesence.

In the absence of a definite cure for the disease, the treatment of whooping cough is a battle with symptoms and complications, and these are so numerous and so various in their manifestations that it is impossible to give general advice. A severe case taxes the ingenuity and experience of a specialist, and so it is apparent that the home treatment, so often depended upon, is highly dangerous. As soon as your child develops a bad cough, send for a physician; and do not grow impatient if he fails to make an immediate diagnosis and give the patient instant relief. As I have said, it is often difficult to detect whooping cough during the first week. It is possible, indeed, for a child to have the disease and yet never whoop, and it is possible, again, for a child to whoop, and yet not have whooping cough. A child who has once had the malady is very apt to whoop for years afterward, whenever it takes cold.

Cleanliness and fresh air are just as important in the treatment of whooping cough as they are in measles or pneumonia. Let the room in which the patient is confined be cheerful and sunny, and whenever possible give it two rooms, so that one may be cleaned and disinfected while the other is in use. If the weather is fine and it is strong enough, it should be taken out for an airing every day. But if the air is damp, or there is a wind, it would best be kept indoors.

The complication most to be feared, during the winter months, is pneumonia. During the summer, particularly if the patient is very young, there is almost equal danger from diarrhea. In order to ward off the latter it is necessary to exercise great care in the diet. The patient's meals should have diluted milk and egg-albumen for their mainstays, and there should be no feeding of raw fruits or red meats, save with the consent of the physician. Among 
infants convulsions are not infrequent, and often they cause death. Despite the appalling fight for breath during the paroxysms of coughing, it is seldom that a patient dies by actual suffocation.

Whooping cough is such a contagious malady, and runs such a long course that it is never safe to keep other children under the same roof with a patient. As soon as the disease is detected, let the other children be sent away at once to some house in which they will be the only youngsters, and keep them away from school for sixteen days. If, at the end of that time, they appear to be in good health, they may be sent back to school.

All of these precautions are necessary because there is good reason to believe that whooping cough is contagious, not only during the whooping stage, but also in the very earliest stage. Thus a child who seems at the moment to have nothing worse than a mild cold may yet spread whooping cough from end to end of a large school. Where a hundred children are exposed to the infection, it is not uncommon for 90 to develop the disease. It is, indeed, one of the most virulent of childhood's plagues, and as I have shown, one of the most dangerous. In the United States to-day, it kills more children each year than scarlet fever.

The room in which a patient sleeps should be disinfected every ten days. In order that this may be done, of course, the patient must be moved to another room. As soon as all is in readiness swab the furniture with a weak solution of bichloride of mercury or carbolic acid. Then close the room tightly and burn a formaldehyde candle. After an hour or so, throw open the windows, and let the fumes of the formaldehyde escape. If this is done early in the morning, it is usually possible for a child to sleep in the room that night.

The virtue of this disinfection lies in the fact that a child recovering from whooping cough sometimes seems to become reinfected, probably from the bed-clothes or other furnishings. In other words, the patient apparently acquires the disease all over again, when on the road to recovery. Disinfection minimizes this danger, and in addition it disposes of all the stray germs that may have wandered in and so reduces the danger of pneumonia and other complications.

It is not wise to let the patient come into contact with other children until at least a month after the whooping has ceased. Even then, it is best that it sleep alone for another month. Before 
the rooms in which it has been housed while ill are used by other children they must be disinfected in a thorough manner. This may be done with the antiseptic solutions and the formaldehyde, using both more freely than in the periodic disinfections, but it is advisable, whenever possible, to have the work done by experts. In all large cities the health department will send men to do it, sometimes for a small fee and sometimes without charge.

There are dozens of patented remedies for whooping cough and all of them now bear the misleading notice "Guaranteed under the Pure Food and Drug Act." The layman fancies that this notice signifies, in some mysterious manner, that the national government endorses the extravagant claims of the makers. As a matter of fact, it does nothing of the sort. All it proves is that the nostrum contains no more of certain specified poisons than is indicated on the label. Innumerable drugs which, under the law, need not be specified on the label, are extremely dangerous.

It may be stated with all due fairness to the patent medicine men, that not one of their cough syrups and elixirs is of value in whooping cough. True enough, some of them may contain drugs which, in the hands of a competent physician, may be of appreciable service, but all of these do far more harm than good if the dosage is not adapted to the peculiar needs of the individual patient, and all of them are very apt to upset the stomach. Vomiting and diarrhea are common enough in whooping cough as it is. Drugs in the stomach are always foes of an uneventful recovery, and the physician, when he gives them at all, does so with great care and great reluctance.

The common home remedies are even worse than the drugstore messes. Those ghastly infusions of camomile and other herbs, so often prescribed by wise old grandmothers to provoke perspiration, and so "sweat out the fever," are the advance agents of pneumonia. So are all the ancient plasters and poultices of the family medicine chest. Let them be anathema!

I sometimes think, indeed, that the degree of civilization of a community may be judged by the contents of its average family medicine chest. In the old days this chest bulged with herbs, barks, roots, soothing syrups, headache powders, lint, salves and ointments. Paregoric was in the place of honor, and behind it stood carboys of arnica and sweet spirits of nitre.

In the future, I fancy, the medicine chest will be smaller and 
less horrifying. It will contain a box of aseptic cotton, a bottle of carbolic vaseline, a bottle of castor oil, a hot water bag and very little else.

\section{QUESTIONS FOR THE MOTHER ABOUT CHAPTER XIII}

Why should whooping cough be especially avoided?

Because the mortality is very high, especially among very young children. Babies who have whooping cough are more likely to develop pneumonia in the winter time and diarrhea in the summer time. Tuberculosis often results from the physical debility caused by whooping cough.

Should a child with whooping cough be isolated?

Yes. Whooping cough is so exceedingly contagious that it is not safe to have other children in the same house with a whooping cough patient.

Should a child with whooping cough be allowed to go to school?

No. One case of whooping cough can infect a school from end to end. Though children with whooping cough are able to run about, they should be kept away from all other children.

What is the best way to get rid of whooping cough?

The room in which the child sleeps should be disinfected every ten days. Whooping cough is so exceedingly infectious that the child can reinfect itself, thus prolonging the disease. Sheets, bedding and clothes should be soaked in carbolic acid solution; woodwork and floors and walls should be washed down with this solution, and a formaldehyde candle burned every ten days.

Is it necessary to have a doctor for whooping cough?

By all means. It is not safe to use any home remedies or patent medicines. Let the doctor watch the little patient very closely. A child with whooping cough should be warmly clothed, but should have plenty of fresh air. 


\section{CHAPTER XIV.-IF YOUR BABY HAD PNEUMONIA}

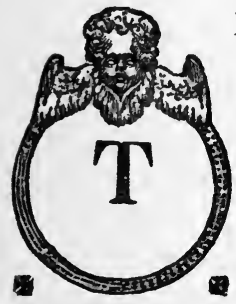

HE sinister distinction of holding first place upon the American table of mortality belongs to pneumonia, a disease of the lungs. It causes more than one-tenth of all the deaths that occur in the United States each year. It slays the babe of a few months and the grandfather of fourscore years. It lays low the rich and the poor, the sturdy and the weak, the overfed and the starving. And it is one of the few diseases that the modern physician can do little to combat. When the patient gets well, it is nearly always nature that works the cure - nature and, be it added, good nursing.

In view of this fact it is plain that every American mother should endeavor to learn something about the malady, for it is upon her, when the patient is a child, that the burden of nursing commonly falls.

Reduced to its elementals, pneumonia is nothing more than a clogging up of the lungs, due to the presence and activity of countless hordes of some breed or other of virulent germ.

As every one knows, oxygen enters the body through the nostrils and the windpipe, as a result of the act of breathing. At its lower end the windpipe divides into two branches-the bronchial tubes -one of which makes off to the right and the other to the left. At the end of each bronchial tube there is a further division, and at the end of each division another one, and so on. The incoming oxygen, proceeding down these constantly dividing passages, comes at last to the ultimate lung-cells.

Now, when virulent germs invade the lungs, the blood and tissues make an effort to paralyze and kill them, and the result of the battle is a mass of débris - dead germs, broken-off lung cells, mucous, dead blood-cells and other things. This débris fills many of the lung-cells and puts thousands of them out of commission. In consequence the blood gets less oxygen than it should get, and the 
heart tries to make up for the deficiency by pumping blood into the remaining clear cells a good deal faster than usual, and by making the lungs breathe faster. This plan works very well for a while, and if the blood makes good progress in killing the invading germs and the débris is quickly absorbed or coughed up, the difficulty will be tided over and the lungs will soon be working normally again. But sometimes so many cells are clogged up that the blood can not get enough oxygen, no matter how hard the heart works, and then there is great danger of collapse and death. Again, the germs may send out poisons which paralyze the heart, and then there is great danger, too. All this proves, you will observe, that pneumonia, though a lung disease, makes its final onslaught upon the heart.

The foremost pathologists in the world have been trying for many years to discover some specific for pneumonia, but so far their efforts have been in vain. That is to say, there is nothing under the sun that will directly kill the germs or directly aid the blood in its war upon them. It is possible, of course, to assist nature by combating the fever which appears with the disease. What the patient most needs is a clean bed and plenty of air. Given these things and a good constitution, the blood will fight the germs, rout them, kill them and get rid of them. The chances are always in favor of recovery.

An attack of pneumonia begins in a manner which suggests a very bad cold. The patient has a chill and a fever and suffers from pains in the side. A cough soon appears and the breath becomes short and quick. The valiant battle of the overworked heart is indicated by a quick pulse and flushed cheeks. Soon there are signs of great exhaustion, with headache, sleeplessness and (sometimes) delirium.

During all of this period the blood is waging a tremendous war upon the invading germs. If it is destined to lose, the exhaustion will grow more and more marked and the patient will die. But if it is destined to win there will come a time-it will be between the fifth and the tenth day-when the patient will suddenly seem brighter. The temperature will fall, the breathing will be more regular, and the violent jumping of the pulse will cease. When this happens it is a sign that the battle is won.

But though the germs have been conquered, it is just at this stage that careful nursing is most needed. The lungs are full of 
purulent wreckage, and the business of getting rid of this is difficult. The attack itself has greatly exhausted the patient, and his strength is next to nothing. Good nursing must recruit it for him-nursing which takes the form of plenty of fresh air and a supply of easily assimilated food.

The fact that pneumonia might be called simply a shutting-off of oxygen shows how important it is to give the patient plenty of air. In several large New York hospitals, indeed, sufferers from the disease are carried to the roof, and kept there day and night. When your child grows ill, move it to the largest and sunniest room in the house, and open the windows. If it is too cold for that, have another room near by, into which the patient may be moved at least three times a day, to permit a thorough ventilation of the sick-room. All unnecessary furniture and all pictures, hangings and other impedimenta should be taken out of both rooms.

It is dangerous to permit pneumonia patients to remain too long in one position. They should be moved about often, and should be frequently propped up with pillows. The notion that the child must be buried in blankets to protect it from "catching cold" is little more than a mere superstition. The child already has the worst of all conceivable colds, and what it needs, beyond everything else, is air and freedom of movement.

When the little patient's temperature ranges alarmingly high, some means should be employed to bring this temperature down, but this means should never take the form of drugs. The use of such things as phenacetine, antipyrin, acetanilid and their combinations is exceedingly hazardous, on account of their interference with the proper working of the heart. Quinine is almost as bad. The best thing to do is to sponge the baby with alcohol or cold water. Next after that comes the use of ice-bags and compresses.

During the bath it is a good plan to rub the child's skin all overof course, very gently. This has a good effect upon the circulation, and tends to prevent delirium and restlessness. In addition, there is probably some more subtle psychic effect. Every one knows how pleasant it is to be gently massaged-how it drives away pain, calms the nerves and produces a feeling of healthfulness and wellbeing. Sleep and comparative comfort usually follow the bath and rubbing down. Upon the reappearance of any nervous symptoms, repeat the bath.

As I have said, it is impossible to aid the body directly in its 
struggle with the pneumonia organisms, but there are countless ways of giving it indirect assistance. When a cough is severe, for example, a good effect is often produced by the inhalation of the vapors of creosote, carbolic acid or menthol. Again, alcohol and other stimulants are often capable of lending the heart a hand at a critical moment. But it is not well for the mother to employ such things on her own responsibility. Have the doctor give you full instructions, and then carry them out faithfully.

There are so many varieties of pneumonia that it would be impossible to specify all of them. What is known as broncho-pneumonia is the most common form among small children. Six times out of ten it appears as a sequel to whooping cough or some other infantile ailment, and is then usually traceable to faulty nursing. It represents, indeed, nothing more than a transfer of the germ of some disease to the lungs.

True lobar pneumonia usually comes on suddenly, like a bolt from the blue, and not as a sequel of some other malady. It is most common between. the ages of three and eight and usually attacks children who have seemed to be perfectly healthy. It always follows the course I have described, whereas bronchial pneumonia may drag on for weeks, and in some cases may become genuinely chronic. The immediate death-rate in lobar pneumonia is higher than in the bronchial variety, but, in the long run, it is less to be dreaded, for it is seldom marked by relapses, and recovery, when it occurs, is always complete.

After a child has had pneumonia, no matter what form of the malady, and convalescence has begun, it is best to take it to the country. The disease leaves the body enormously thirsty for fresh air; and fresh air, in a large city, is almost a curiosity. Besides that, a change of scene is always of great benefit during recovery. Unluckily, pneumonia confers no durable immunity. As a matter of fact, the recovered patient is more liable to the disease than it was before the attack. In addition, its weakened lungs afford unusually good soil for the germs of other maladies, too, and one of these is tuberculosis. Fresh air is the only thing that can reduce this liability.

At times, pneumonia sweeps through an entire household, and in all cases it is well to isolate the patient, particularly when there are other children in the house. Your own child may be protected against pneumonia by very simple precautions. See that it gets 
wholesome, easily digested food and that it has plenty of air, day and night. Too much coddling is the principal cause of childish ailments.

You may think that fresh air causes colds, but as a matter of fact the very reverse is true. The child that is always taking cold is the child who has been coddled and whose mode of life ill adapts it to meeting the vicissitudes of existence here on earth. It is part of life for all of us, now and then, to stand in drafts and to get our feet wet. No matter how much we try to avoid it, we must do so at frequent intervals. Therefore, the thing to do with a child is, not to make a vain attempt to protect it against accidental and inevitable exposure, but so to rear it that it will be able to face such exposure without damage. A cold is always a sign of a low power of resistance. The entirely healthy human being never takes cold.

Therefore, when your baby begins to cough and snuffle, send for your doctor and have him examine it. The very fact that it is coughing is proof that it needs attention. The doctor's visit, if it is made in time, may head off an attack of pneumonia. Most mothers regard a cold as a trivial and harmless thing, but, as I have shown, it is not. The difference between a cold and pneumonia is one of degree only, and not one of kind. Both are definite infections, and both prove, with equal force, that the little patient is not as well fitted as he should be to survive in the struggle for existence.

In conclusion, let me warn all mothers who read this chapter to remember that there is no reason for flying into a panic when the doctor's verdict is "pneumonia." Given good and faithful nursing and obedience to the doctor's orders, there is no reason why your child should not get well. In all cases, no matter how serious, the chances are in favor of recovery.

\section{QUESTIONS FOR THE MOTHER ABOUT CHAPTER XIV}

What is the one preventive as well as cure for pneumonia?

Fresh air.

How will fresh air cure pneumonia?

Pneumonia is a disease that shuts off oxygen from the lungs. Therefore the patient needs to get as much fresh air as possible. 
Its bed should be put on the piazza or roof or under a large window.

How will fresh air prevent pneumonia?

It builds up the body, makes a child hardy, and its blood able to resist cold and pneumonia germs. Keep the children out of doors all day. Let them sleep in the open air at night and do not worry about pneumonia.

Why should a cold be treated as if it were the most serious of diseases?

Because it is a sign that the child is run down; that its body is in a condition to be attacked by other germs. Because a cold neglected may lead to pneumonia or even tuberculosis. Because a cold is often a symptom of a contagious disease. If the child is not isolated, the family or school may be exposed to contagion.

Why should a child with a cold have a thorough physical examination by a doctor?

Not only that he may prevent the cold from developing into something more serious, but because it is a sign that the child needs a change of air, of food or habits. It is often a sign that the child has adenoids, and adenoids may open the way for pneumonia or tuberculosis.

Why should a pneumonia patient have the constant care of a physician and a graduate nurse?

Because the death rate from pneumonia is very great and is constantly increasing; because the disease is so severe and short. Three, two or even one day may decide whether an attack of pneumonia means life or death.

What care should a convalescent have?

He should have his lungs thoroughly examined, have a "culture" taken to be sure he has not tuberculosis. He should take pains to avoid fatigue, over-heated rooms; should make a point of eating plenty of nourishing food, and of keeping out in the fresh air. 


\section{CHAPTER XV.-NEED EVERY CHILD HAVE MEASLES?}

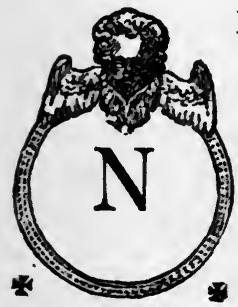

EXT to the common cold, measles is probably the most wide-spread of all infectious diseases, at least in civilized countries. Almost everyone gets over it, many do not. This has led to the popular idea that measles is something to be regarded lightly, and that it is best, all things considered, for a child to take it and have it over. Nothing could be further from the truth. In itself, perhaps measles is seldom a direct cause of death, but too often it leaves the body in a very debilitated state, and other, and worse, maladies come in its train. Thus, like influenza, it is chiefly to be feared, not on its own account, but on account of the things that follow it.

No one has yet succeeded in tracking down, with certainty, the germ that causes measles. We know that the cause is a germ, because its effects and mode of multiplication are exactly those of other germs, but beside the fact that it is an animal parasite we know very little else about it. Until we learn more, it will be impossible to make a direct war upon it. Even now, of course, we can take measures to prevent its spread from one person to another, and after it has begun its work we can deal with symptoms and complications it produces, but we know of no way to kill it, once it has invaded the body, and we know of no way to limit or modify its activity there.

Fortunately for us, nature knows more than we do. As soon as the measles germ enters the body, nature begins to battle with it, and in the vast majority of cases she succeeds in stamping it out. This battle is begun automatically, and-unless death intervenesit always proceeds in a more or less regular manner. In consequence we say that measles is a self-limiting disease, which means that it runs a clearly-marked course, beginning with the first appearance of the germs in the body and ending with their complete destruction and expulsion. 
The more obvious signs of measles-the fever, the lassitude, the sore eyes, running nose, and sore throat, and beyond all, the red rash-are familiar to every one. There are, in addition, several signs which give earlier warning, but which are seldom perceptible, save to the physician. One of them is Koplik's sign, so called after the New York pathologist who first noticed it. It consists in the appearance of small blue-white specks on the mucous membrane lining the inside of the cheeks. These specks usually appear two or three days before the rash and so they give the physician a chance to be forewarned and forearmed. They explain why it is that when a child complains of feeling ill and shows a rising fever, the doctor usually makes a thorough examination of its mouth.

After a child has been exposed to measles, it takes from eleven to fourteen days for the disease to develop. The first symptom is a general feeling of illness and uneasiness, with the signs, perhaps, of a bad cold in the head. Then the eyes begin to water, the temperature rises, the throat becomes sore, there is a cough, and on the third or fourth day the characteristic eruption appears. As a rule, it is first seen along the edge of the hair-on the forehead or neck, or behind the ears. It is made up of small, dark-red spots, often some distance apart and flat with the skin. These spots soon begin to swell and multiply, and in a short while the whole face is covered with them and they begin to appear on the neck and chest, and so on down to the feet. By the time they reach the feet, they are commonly beginning to dry up upon the face. Usually they are in groups, with areas of clear skin between, but sometimes they cover the face so thickly that scarcely a speck of clear skin is to be seen. At such times, the whole face is swelled and the eyes are almost closed.

There are three or four days of this, and then the little pustules begin to grow pale and dry. This is the period of desquamation, or shedding. The dead skin breaks off into small scales, much resembling bran, and the new skin begins to appear underneath. In scarlet fever the skin comes off in large patches, but in measles the scales are small. Often, indeed, they are so small that they are scarcely noticed.

This shedding continues, as a rule, from five to ten days, though occasionally it may be prolonged to two weeks. It is accompanied by annoying itching, and there is commonly some cough too, and 
a lingering weakness in the eyes, but otherwise the patient begins to feel perfectly well again. The appetite returns, the fever has abated, and, if all has gone well, there is nothing amiss in throat or lungs.

Sometimes the rash in measles is so severe that the small blood vessels in the skin are broken down, and the blood in them comes out. The blood collects under the surface of the skin in small dark patches, much as in a bruise or black eye. This condition was described by the older doctors as "black measles," and it was believed that death almost invariably followed. But, as a matter of fact, the appearance of these dark spots need not cause a panic. As a rule, true enough, they indicate a case worse than the average, but they have been noted, also, in comparatively mild cases, and in themselves they do no harm. It often happens that a few such haemorrhagic eruptions appear in the course of an ordinary case.

As I have said, nothing can be done to cure measles, as we can cure malaria, diphtheria or a broken arm. The disease must run its course, and we can never even tell how long that course is going to be, save very roughly. But it is perfectly possible to guard the little patient against the disastrous complications which lurk along the trail of the measles germ, and it is possible, too, to relieve much of the patient's suffering. In accomplishing this, the nurse plays a part more important perhaps than that of the doctor.

As soon as a child grows ill and feverish, and begins to complain of discomfort in the eyes and nasal passages, it should be put to bed in a well-ventilated, darkened room, and the physician should be summoned. So many infantile maladies begin in the same way that it is often impossible, at this stage, to say whether the little patient is developing measles, scarlet fever, influenza, or merely a cold, but it is always best, whenever it shows a fever, however slight, to put it to bed. In a day or two, more certain diagnosis will follow the first doubt.

Let me say here with all possible emphasis, that putting a child to bed does not mean burying it beneath a matterhorn of woolen blankets. There is a popular notion, that, in all maladies accompanied by fever, a vigorous and constant perspiration is beneficial and necessary, but this is scarcely true. Sweating will not modify the course of measles, and neither will bad air, except in an un- 
favorable way. See that the patient is well protected from all draughts, but let the blankets be light enough for comfort, and make sure that there is constant ingress of fresh air into the room.

As a help toward that sweating which woolen blankets, however thick, only partly achieve, it is customary, among amateur nurses, to employ vast doses of various hot teas. All such disgusting messes should be thrown to the dogs. Camomile, sassafras or what-not-they do a lot of harm and no good at all. It is difficult to make the average grandmother believe that camomile is a fraud, and so, when she recommends it and you refuse to administer it, she will go away offended, but it is far better to offend her than to injure your child. All the little patient needs, in the way of drink, is plenty of cooled water-not ice water, but water of the ordinary hydrant temperature. Do not keep a pitcher full in the sick-room, but draw a fresh glass of a pure or boiled water that has been cooled whenever it is wanted. Day or night, never deny the child a drink.

Regarding the food to be given to the patient, it is best to consult the attending physician in the particular instance. In an ordinary case of measles, the child will be satisfied with milk, soft-boiled eggs and meat broths during its few days of severe illness, and may approach its usual diet soon thereafter, but in case there are complications, particularly in the digestive tract, great care in feeding must be exercised. Have the doctor draw up a bill of fare and fix the meal times, and then stick to the schedule religiously. A feverish child requires very little food and it is best never to try to force it to eat.

The patient's eyes will probably be inflamed and painful. Keep them clean by swabbing them every few hours with a little mop of sterilized cotton that has been dipped into a solution of boracic acid. The cotton comes in boxes to be had for ten cents or a quarter at any drug store. Never use ordinary raw cotton, for no matter how clean it may seem, it is always full of irritating particles and the germs of various diseases. The boracic acid is a near relative to borax and may be had at the drug-store. Put a tablespoonful into a tumbler of water and use the clear solution.

If there is so much discharge from the eyes that the lids stick together, dip a piece of the sterilized cotton into vaseline and gently smear the edges of the lids. Sometimes the eyes-are so painful and so much inflamed that it is necessary to apply ice-packs to 
them. When this is necessary, the doctor will show you how to do it.

There is a great deal of itching in measles, particularly after the dead skin begins to shed. To relieve it, apply a thin film of vaseline-either the plain or the carbolated. Besides reducing the itching, this will loosen the scales and so help the process of desquamation. But never rub the skin! The friction of the washrag or cotton and the clothing is all that nature needs.

During the few days of fever, of course, the child need be bathed only at the doctor's orders. As soon as the shedding begins it should have a daily warm bath. This should be given with the room warm and all the windows closed, and it should not be prolonged. Use a very soft wash-cloth or absorbent cotton and little, if any, soap; and after drying, anoint all those parts of the body upon which the rash has appeared with vaseline. The physician may prescribe some other ointment, but if he does not it is best to use only vaseline. The common drug-store salves and ointments may do a great deal of harm.

The child's cough, headache, sore throat and other discomforts must be combatted, not by the nurse, but by the physician. Aside from its simple food and its plentiful supply of cooled water, it should take nothing into its stomach that has not been prescribed by its medical attendant. There are dozens of grandmothers' elixirs for the various symptoms of measles, and all of them are abominations. From boneset tea to sweet spirits of nitre they are dangerous frauds, one and all.

Measles is an exceedingly contagious disease, but its virulence, unlike that of scarlet fever, does not last very long. As soon as a case appears in a household, all of the other children should be kept from school, but it is unnecessary to send them out of the house. The room in which the patient is being nursed should be isolated from the rest of the house, with as rigid a quarantine as if the contagion was always fatal. If the mother is the nurse, she should keep away from the other children until at least two weeks after the patient has recovered. It is possible for a child to take measles by merely passing the open door of a room in which a patient is confined.

If, as often happens, there are two patients at the same time, it is best, whenever possible, to put them into separate rooms. This is because the more dangerous maladies which sometimes 
follow or complicate measles, such as pneumonia, are apt to be communicated from one patient to another. Herein, no doubt, we find an explanation of the fact that epidemics of measles are always more severe in boarding-schools and orphan-asylums than among children at home. One patient, developing pneumonia or diphtheria, communicates it to many others.

Inasmuch as measles is already contagious before its outward signs appear-that is, during the period of incubation, or breedingit is exceedingly difficult to protect a child against it, particularly if the child goes to school or to Sunday School, or otherwise associates with its fellows. But in the case of weakly children, it is well to make extraordinary efforts to secure this protection, for measles, in such children, very frequently leads to pneumonia, chronic bronchitis, and even tuberculosis. If, after an attack, the patient continues to cough and to remain weak, it should be sent into the country; preferably, to the mountains. The seeds of life-long illness and early death are sowed by apparently mild attacks of measles.

A week after the last signs of shedding have disappeared it is safe to permit the patient to mingle again with other children. But before the room in which it has been confined is used as a sleeping apartment, it should be thoroughly disinfected. The measles germs do not cling to life very vigorously, and outside of the human body they soon die, but it is well to take no chances.

\section{QUESTIONS FOR THE MOTHER ABOUT CHAPTER XV}

Why should every precaution be taken to protect a child from measles?

Because though it is not often fatal, it weakens the child so that it readily takes other diseases.

What are the first signs of measles?

A cold, fever, sore throat and weariness; later a red rash and blue-white spots inside the cheeks.

Why should a child with measles be quarantined?

Because measles is contagious and it is not fair to other children to give them a disease that may lower their vitality and pave the way for other diseases.

How long should a child that has been exposed to measles be kept away from other children? 
It takes from eleven to fourteen days for the disease to develop.

What precautions should be taken to prevent the spread of measles?

Measles should be reported to the Board of Health; a sign MEASLES should be put on the door. No one but the nurse should be allowed to go into the child's room or to pass the door when it is open. The room should be thoroughly fumigated before it is used again.

What are the special precautions to prevent bad after-effects from measles?

The room should be kept dark, and the child should not be allowed to read, write or sew or to use its eyes at any close-range work. Great care should be taken that the child does not catch cold. This does not mean that all the windows should be kept closed. Fresh air in a sick-room is the best preventive of colds. The lungs and throat of a child should be thoroughly examined after measles, and it should have rest, nourishing food and outdoor life until its health is thoroughly restored. 




\section{UNIVERSITY OF CALIFORNIA LIBRARY}

\section{BERKELEY}

Return to desk from which borrowed.

This book is DUE on the last date stamped below.

FEB 21959

$F E B \quad 21959$

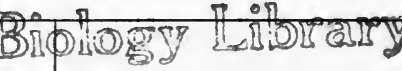



r.

\begin{tabular}{cc}
\hline \\
\hline
\end{tabular}

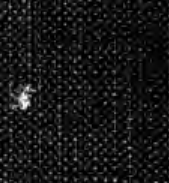

\%.\%. \%

\begin{tabular}{|c|c|}
\hline \\
$*$
\end{tabular}

\%

\begin{tabular}{|c|c|c|}
\hline & & \\
\hline
\end{tabular}

\%

\% $\%$ \%

\%

\%

\%

\%

(19.8\%

6.8.

\%

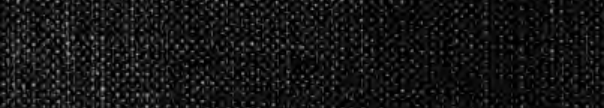

